\title{
Flowability, strength and permeability characteristics of self- compacted concrete made with basalt fibers
}

\author{
1James H. Haido, ${ }^{2}$ Samadar Salim Majeed, ${ }^{3}$ Mehmet Karpuzcu \\ ${ }^{1}$ Department of Civil Engineering, College of Engineering, Univesrity of Duhok, Kurdistan Region of Iraq \\ ${ }^{2}$ Architectural Engineering Department, Nawroz University, Kurdistan Region of Iraq \\ ${ }^{3}$ Civil Engineering Department, Faculty of Engineering, Hasan Kalyoncu University, Turkey
}

\begin{abstract}
Basalt fibers are new generation of natural concrete additives to arrest its micro-cracking and consequently improve concrete strength. The properties of self-compacted concrete (SCC) made with basalt fibers have not been studied extensively. In present work, the properties of fresh and hardened SCCs have been investigated with considering fibers content. Permeability of SCC for water and chlorite has been covered as well. It is demonstrated that fiber content less than $0.25 \%$ has no remarkable effect on flowability performance of fresh SCC. Concerning hardened SCC, the degradation of its mechanical properties has been noticed as $22 \%$ with increasing fibers content to $1.0 \%$. The sorptivity of basalt fiber SCC is obviously dropped due to the nature of used fibers and their absorption.
\end{abstract}

Keywords: self-compacted concrete; basalt fibers; permeability tests of fibrous concrete

\section{Introduction}

Concrete is the mostly consumed constructional material due to its resendable costs of components, durability and proper behavior at service loading [1]. The tensile strength of concrete is low like any brittle material with low ductility [2-6]. Thus, fibers can be regarded as main factor to improve this defect in concrete via arresting micro cracks and consequently enhance its mechanical properties [1, 7-16]. Nowadays, there are many sorts of these fibers, that are widely used in concrete production, namely, steel, polymeric, glass, carbon and basalt fibers [17-21]. Basalt fibers are modern industrial additive for concrete fabrication and they are manufactured with low costs compared to other fibers [22]. Natural basalt rocks are row material for basalt fibers production with advantages of

Academic Journal of Nawroz University

(AJNU) Volume 9, No 1 (2020).

Regular research paper: Published 4 March 2020

Corresponding author's e-mail : samadar.s@nawroz.edu.krd Copyright (C2018 1'James H. Haido, 2Samadar Salim Majeed, ${ }^{3}$ Mehmet Karpuzcu. This is an open access article distributed under the Creative Commons Attribution License. reasonable strength to shear action and chemical attacks [22-24]. Encouraging results have been obtained with using these natural fibers in recently studies dealt with micro-reinforcement of concrete [25-28]. The influence of basalt fibers volume fraction on the mechanical properties of fibrous concrete, such as compressive strength, elastic modulus and energy absorption, has been lately investigated. Ayub et al., [29] examined mechanical properties of high strength basalt fiber concrete with respect to its fiber dosage. It is demonstrated that there is slight effect of this fiber on the compressive strength of concrete; while remarkable improvement was achieved in the direction of tensile strength. Toughness of basalt fiber reinforced concrete has been studied by Jiao et al., [17]. Nuclear magnetic resonance pore test was adopted in their experimental program. Records reveal that fibers dosage up to 7.5 $\mathrm{kg} / \mathrm{m}^{3}$ has significant contribution in increasing residual stress under same concrete deformation. Wang et al., [1] conducted experimental work to estimate the 
mechanical and physical properties of basalt fiber reinforced concrete with respect to length and dosage of fibers. Experimental data indicated that early cracks due to the shrinkage decrease with increasing of fibers content especially with using their volume fraction of $0.2 \%$ no cracking was observed. The fracture elongation and tensile strength of basalt fiber reinforced concrete have been studied by Sim et al., [21]. They demonstrated that the introducing of basalt fibers in the concrete can enhance its strength by 0.5-1.0 times; while the fracture elongation was increased by around 4 times in comparison to ordinary concrete. The impact and damage resistance of basalt fiber concrete has been inspected in the experimental work of Branston et al., [30] and Fu et al., [31]; where high strain rate loading was applied on the samples and nonlinear constitutive models were proposed. Properties of fresh basalt fiber concrete via slump or workability test were studied by some researchers $[32,33]$ who checked the effect of fibers dosage on the workability; they concluded that the slump of this concrete is inversely correlated with fibers volume fraction. Ma et al., [34] highlighted that the change in length and dosage of presoaked basalt fibers does not has influence on the concrete compressive strength. Insignificant effect of fiber content (i.e. $0.02 \%-0.3 \%$ ) on the compressive strength of basalt fiber concrete has been proved as well on other previous studies [35-38]. Thus, the basalt fibers role in the direction of enhancing mechanical properties of concrete is still not obvious based on the conclusions drawn in the literature. It is worth to mention that the influence of basalt fibers introducing on the selfcompacted concrete behavior has not examined extensively; further studies in this direction are considered essential. In current work, the characteristics of fresh and hardened basalt fiber SCC have been investigated comprehensively with consideration of different fiber volume fractions.

\section{Methodology}

\subsection{Materials}

Ordinary Portland cement with specific gravity of 3.15 and specific surface area of $327 \mathrm{~m}^{2} / \mathrm{kg}$ was employed in the production of SCC mixtures as well as normal concrete mixture.

In the production of SCC mixtures, silica fume, which is commercially available, was used as pozzolanic material. The specific gravity and specific surface area values of silica fume are 2.2 and $369 \mathrm{~m}^{2} / \mathrm{kg}$, respectively. The used silica fume consists of high amount of $\mathrm{SiO}_{2}$, more than $90 \%$. In addition, the specific surface area of silica fume measured regarding to Brunauer-Emmett-Teller (BET) theory was between 15 and $28 \mathrm{~m}^{2} / \mathrm{g}$.

The aggregate used in the present self-compacting concrete was a mix of river sand and crushed coarse aggregate with a specific gravity of 2.61 and 2.66, respectively. Both aggregate types conforming ASTM C127 [39] and C128 [40] were provided from local sources. The sieve analysis results for river sand and crushed coarse aggregate conducted regarding ASTM C136 [41] were presented in Table 1.

Current basalt fiber having high performance was provided from Construction Vision Chemicals (CVC) Company, Turkey, with the commercial name of Fiber MF Concrete. The diameter of basalt fiber employed in this study is $16 \pm 2 \mu \mathrm{m}$ with length of $24 \mathrm{~mm}$. The properties of the used basalt fiber (Fig. 1) are submitted in Table 2.

In this study, Hyperplast PC200, which is polycarboxylic polymers based and commercially available chemical admixture, was used in the selfcompacted concrete production to obtain the desired workability. The technical properties of the superplasticizer are presented in Table 3. 
Four different concrete batches, for self-compacting concrete, were designed; many trial batches were produced and they were tested for 28-day compressive strength. The work herein mainly investigates the influences of basalt fiber utilization in the selfcompacting concrete (SCC) production on the workability, mechanical, and permeability properties. The total binder content of $570 \mathrm{~kg} / \mathrm{m}^{3}$ and water-tobinder ratio $(\mathrm{w} / \mathrm{b})$ of 0.3 were designated in all four mixtures. The silica fume, which was employed as $10 \%$ of total binder content by weight, was used as cementitious material instead of cement. In the production of SCC mixtures, four basalt fiber volume fractions of $0,0.25,0.5$, and $1 \%$ were assigned by total concrete volume. The detailed SCC mixture proportions are presented in Table 4.

In the current study, a power-driven rotating drum mixer having 50-liter capacity of 50 liters was used in the production of concrete mixtures. SCC mixtures were mixed and batched according to a special procedure; however, there is a little difference between the production sequence and duration of SCC without and with basalt fiber. By this special production procedure, it was targeted to procure the same uniformity and homogeneity in all SCC mixtures. The order of this special production procedure for SCC mixture without basalt fiber includes putting the aggregate mixtures into the drum and revolving them for one minute to achieve aggregate mixed homogenously. Then, the water was added onto the aggregate mixture and mixing was continued one minute extra. The binder (cement and silica fume) was introduced thereafter on the wetted aggregate and the matrix was mixed for one minute. Afterwards, basalt fibers were mixed with the batch for five minutes. Finally, the solution of superplasticizer and water was poured onto the mixture and mixing was kept on for three minutes and the workability tests were carried out. As soon as the workability tests were ended, the fresh mixtures were molded and the specimens were wrapped with plastic sheets for 24 hours. For one day, the specimens were kept in the casting room, in which the temperature was $20 \pm 2{ }^{\circ} \mathrm{C}$. Then, the demolded specimens were put in water pool for curing for 28-day water until testing. Generally, it is suggested that drinkable water must be used in concrete production. Consequently, the drinkable water was used in the concrete production.

\subsection{Methods}

\subsubsection{Workability Tests}

Slump flow diameter and time, V-funnel flow time, Lbox height ratio, and J-ring flow diameter and time tests were carried out to examine the workability characteristics of SCC mixtures produced in this study. The slump flow diameter and J-ring flow diameter tests were performed to indicate the flowability (in unconfined condition) of SCC mixtures. J-ring and Lbox tests were carried out to identify the passing ability class. Moreover, the viscosity of SCC mixtures was measured in terms of the slump flow time and V-funnel flow time tests. During the performing the slump flow, V-funnel, and L-box tests, the guidelines and specifications suggested by EFNARC [42] committee were followed whereas the J-ring test was carried out regarding ASTM C1621 [43].

By performing slump flow test, two different characteristics of SCC mixture can be identified, flowability and viscosity. Slump flow diameter representing the flowability to measure T50 flow time representing the viscosity of SCC mixture.

V-funnel flow test was utilized in present work to describe the indirect viscosity characteristic of the SCC mixtures, herein, the term indirect viscosity means the viscosity characteristic achieved from this test is based 
on the flowing rate. In order to assess the segregation in the SCC mixtures, V-funnel flow time test was repeated after first time carrying out the test, however, during the second time the fresh SCC mixture was kept in the funnel for five minutes and then it was permitted to flow out through the trap gate.

L-box test for SCC was conducted to describe its passing ability performance. Two different L-shaped test equipments, containing two or three rebars have been employed. The confined spaces are simulated, according to the EFNARC [42], by using L-box test equipment with two reinforcing bars and narrow openings are simulated by using L-box test equipment involving three reinforcing bars.

J-ring flow test (Fig. 2) was also performed in current endeavor with respect to ASTM C1621 [43]. The test apparatus consists of sixteen equally spaced 16-mm rebars on a $300-\mathrm{mm}$ diameter circle and a ring with a thickness of $25 \mathrm{~mm}$ placed on these $100-\mathrm{mm}$ height rebars. The flow diameter, T50 flow time, and height difference in flowed SCC mixture were measured to assess the flowability and filling ability of the SCC mixture.

\subsubsection{Mechanical Tests}

The recommendations and specifications provided in ASTM C39 [44] were followed for performing the compressive strength of SCC mixtures. Besides, to reveal the strength development by time and to see the silica fume effect on the compressive strength, the test was carried out at the ages of 7 and 28 days. Two different shaped 100-mm cube and diameter of 100-mm and height of $200-\mathrm{mm}$ for the cylindrical specimens were taken to conduct the compression test. Also, the main objective of this study was to investigate the temperature effect on the mechanical properties of the SCC mixtures. In the current study, the results reported for the compressive strength of the SCC mixtures are the average of three compressive strength values for each mixture.

Elastic modulus and Poisson's ratio of the SCC mixtures were appointed regarding ASTM C469 [45]. The cylinder specimens were handled to conduct the testing procedure stated in ASTM C469 (2014). The test was performed on three specimens and their average was submitted as the result of elastic modulus for each mixture.

Splitting tensile strength test was provided in accordance with ASTM C496 [46]. The cylindrical specimens with diameter of 150-mm and height of 300$\mathrm{mm}$ were employed to perform this test. The experiment was carried out on three samples and the splitting tensile strength result for each mixture reported in this study is the average of these three specimens.

Three-point bending test was considered to evaluate the flexural strength of the SCC prisms; the test was conducted regarding to ASTM C78 [47]. Three prismatic specimens with size of $100 \times 100 \times 400-\mathrm{mm}$ were tested and their average was submitted as the result for flexural strength.

\subsubsection{Permeability Tests}

The amount of water pass through the capillary pores of the concrete was measured by the sorptivity test. This test was carried out on the specimens (Fig. 3) with 100-mm diameter and 50-mm height that were attained by cutting the $\phi 100 \times 200-m m$ cylindrical specimens. In order to achieve reliable results from performing this test, the specimens are kept in an oven to maintain oven-dry state specimens until the mass of the specimens becomes constant. To prevent crack occurrence due to the temperature, the oven has a temperature of $50 \pm 5{ }^{\circ} \mathrm{C}$. The rounded sides of the specimens are covered with paraffin to prevent water absorption from the sides and the cut surface is exposed 
to the water during the conducting of the test as schematically demonstrated in Fig. 4. The water penetration depth of the SCC mixtures was measured according to TS EN-12390-8 [48]. The test was conducted on three cylindrical specimens and their average were reported as the result. The cylindrical specimens are exposed to $500 \pm 50-\mathrm{kPa}$ downward pressure water for 72 hours as indicated in Fig. 5. The specimens are knapped into two pieces from the middle after a 72-hour water pressure application. Afterwards, the highest water penetration depth on the knapped surfaces was measured for each specimen. If the concrete is going to keep in touch with aggressive or moderately aggressive media, the water penetration depth should be more than 30 and $50 \mathrm{~mm}$, respectively.

The resistance of the SCC mixtures to chloride penetration was measured as well; the top and bottom parts of $\phi 100 \times 200-m m$ cylindrical specimens were used in this test while the middle part of these specimens was used in the conducting of the rapid chloride permeability test. For this reason, the test was carried out on three $50-\mathrm{mm}$ disk specimens and their average was submitted as the result. To eliminate the defects arising from the segregation and/or bleeding, the samples taken from the middle portion of the specimen are employed in the test. The preparation of the 28-day water cured specimens for the test was made with respect to recommendations provided in ASTM C1202 [48]. Then, the prepared specimens were placed between the sodium hydroxide $(\mathrm{NaOH})$ and sodium chloride $(\mathrm{NaCl})$ contained cells. In this context, the faces of the specimens were kept in touch with $0.3 \mathrm{~N} \mathrm{NaOH}$ and $3 \% \mathrm{NaCl}$ solutions. After placing the specimens between these cells, a direct current of $60 \pm 0.1$ volts was applied to the faces for the 6-hour period. During the test, the current traversing through the specimen was recorded and then, the total charge passed through the specimen was calculated by applying the Simpson's integration. As a result, the total charge in terms of coulombs was determined from the recorded current and the time history. The typical rapid chloride permeability test photo has been presented in Fig. 6 .

\section{Results and Discussion}

\subsection{Workability Tests Records}

The slump flow diameter results for the SCC mixtures manufactured in this study have been presented in Fig. 7 . The results indicated that the plain SCC mixture that produced without basalt fiber had a slump flow diameter value of $740 \mathrm{~mm}$, which can be classified as SF2 flow class according to the EFNARC [42] specifications. As stated in these guidelines, this type of SCC mixtures can be utilized for the many types of normal applications such as walls, columns, etc. The results also revealed that the utilization of basalt fiber in the SCC production worsened the flowing performance of the SCC mixtures. After the basalt fiber volume fraction of $0.25 \%$, the SCC flowability class changed from SF2 to SF1. Namely, the slump flow diameter of the SCC mixtures dramatically dropped below the $650 \mathrm{~mm}$ when the basalt fiber volume fraction increased from 0.25 to 0.50 or $1.00 \%$. This is an expected impact of fiber utilization in concrete production. The main reason for the reduction in the slump flow diameter by using of basalt fiber can be explained as the basalt fiber particles absorb mixing water and also make the cement paste much more cohesive since the basalt fiber particles are in microscale case. The segregation and bleeding in the SCC mixtures were visually examined in this study. For this, the fresh concrete on the slump flow table was used. After the slump flow diameter and time tests finished, a little time was waited to observe there is segregation and bleeding or not. The typical photographic view of the SCC mixture on the slump flow table has been 
indicated in Fig. 8. The photograph belongs to the SCC mixture produced with $0.25 \%$ basalt fiber volume fraction and when the photograph is examined, it can be easily seen that there is no segregation and bleeding in the concrete. The same results were beheld in all mixtures.

Another flow diameter test for the SCC mixture is the Jring flow diameter test. In order to express the reliability and robustness of the study and test results, J-ring flow diameter test was also carried out. The variation in the J-ring flow diameter of the SCC mixtures versus the basalt fiber volume fraction has been shown in Fig. 9. The results procured from this study supported the findings attained in the slump flow diameter test. The utilization of the basalt fibers in the SCC production decreased the flowability performance. Especially, after the basalt fiber volume fraction of $0.25 \%$, the amount of decrement in the flowability performance was increased. The main reason for this is the utilization of the mixing water by the basalt fiber particles and that caused both the decreasing of the workability and the increasing of the cohesiveness of the cement paste. The similar effect of the basalt fibers utilization as observed in slump flow diameter can be seen in $T_{50}$ slump flow time. The variation in the $T_{50}$ slump flow time with respect to the basalt fiber volume fraction has been indicated in Fig. 10. The increment in the $T_{50}$ slump flow time was observed by increasing the basalt fiber volume fraction. The plain SCC mixture that produced without basalt fiber has the $\mathrm{T}_{50}$ slump flow time of $2.1 \mathrm{~s}$ whereas the SCC mixtures produced at the basalt fiber volume fractions of $0.25,0.50$, and $1.00 \%$ have the $\mathrm{T}_{50}$ slump flow time values of 3.2,3.9, and 4.2, respectively. This delaying in the flowing time is due to high cohesiveness in the cement paste caused by fiber particles. Accordingly, all SCC mixtures produced in this study can be classified as viscosity class of VS2 regarding the EFNARC [42] guideline.

The $T_{50}$ flow time (Fig. 11) values procured from the Jring test indicated an increment trend by the increasing of the basalt fiber volume fraction. The plain SCC mixture that does not include basalt fiber has the $T_{50} \mathrm{~J}$ ring flow time of $2.4 \mathrm{~s}$ whereas the SCC mixtures produced with the basalt fiber volume fractions of 0.25 , 0.50 , and $1.00 \%$ have the $\mathrm{T}_{50} \mathrm{~J}$-ring flow times of 4.0, 5.1, and $6.4 \mathrm{~s}$, respectively. A similar increase was observed in the slump flow time test. This is directly related to the decrement in the cohesiveness of the cement paste by basalt fibers addition. Since there is no definite classification for J-ring flow time provided by the EFNARC [42], presenting the result of this test will provide a piece of extra information about the indirect viscosity of the SCC mixtures.

The $\mathrm{T}_{50}$ slump flow and $\mathrm{V}$-funnel flow times were both used to describe the indirect viscosity of the SCC mixtures. The variation in the V-funnel flow time of the SCC mixtures produced in this study versus the basalt fiber volume fraction is shown in Fig. 12. The plain SCC mixture, namely the mixture without basalt fiber, and the SCC mixture produced with basalt fiber volume fraction of $0.25 \%$ have the $V$-funnel flow time of 6.0 and 7.4 s. According to these V-funnel flow time values, SCC mixtures can be regarded in the viscosity class of VF1 according to the EFNARC [42] specifications. However, the SCC mixtures manufactured with the basalt fiber volume fraction more than $0.25 \%$ can be classified in the viscosity class of VF2. V-funnel flow time after keeping the fresh SCC in the funnel for 5 minute was also measured to examine the segregation in the mixture. The results achieved from this test were also presented in Fig. 12. Basalt fiber utilization also caused retardation in the V-funnel T5 flow time. The difference between the V-funnel flow time and T5 flow 
time indicated that there is segregation in the SCC mixtures produced in this study since the difference between two flow times is about $3 \mathrm{~s}$ in all mixtures.

The passing ability class of the SCC mixtures manufactured in this study was determined regarding the L-box height ratio that was performed according to the specifications provided in the EFNARC [42]. The results achieved from this test have been graphically presented in Fig. 13. It can be easily seen from this graph that the plain concrete, without fiber, has the Lbox height ratio of 0.88 and the using of basalt fiber in the concrete production caused systematical reduction in the L-box height ratio. Besides, the results indicated that all SCC mixtures can be regarded in the passing ability class of PA2 except the SCC mixture produced with basalt fiber of $1.0 \%$ volume fraction. Although the mixture produced with fiber volume fraction of $1.0 \%$ is grouped at the out of passing ability class, its L-box height ratio is 0.78 .

J-ring height difference, which is the difference between the highest and lowest concrete levels after removing the slump cone, was measured to indicate the passing ability characteristics of the SCC mixtures manufactured in this study. The test results in accordance with basalt fiber volume fraction have been graphically presented in Fig. 14. The results indicated that the using of the basalt fiber caused the decreasing of the passing ability performance of the concrete. The highest J-ring height difference was measured in the SCC mixture including $1.00 \%$ basalt fiber while the lowest value was achieved in the plain SCC mixture. Thus, it can be concluded that the addition of the basalt fiber and increasing its content causes certain decreasing levels in the flowing, filling, and passing ability of the SCC mixtures. However, visual observation of the slump and J-ring flow tests revealed that using basalt fiber in the SCC production made the concrete more cohesive that means better segregation and bleeding resistance characteristics.

\subsection{Properties of Hardened SCC}

Variation in 7-day and 28-day compressive strengths of the SCCs with respect to basalt fiber volume fraction has been shown in Fig. 15. The results revealed that the 7-day compressive strength values of the SCC mixtures are about $75 \pm 5 \%$ of the 28 -day compressive strength. In addition, it was observed that the introducing of basalt fiber to SCC decreased the compressive strength values at both ages. This can be attributed to low workability and lightening in concrete weight with introducing fibers. The 7-day compressive strength values of the SCC mixtures produced in this study varied between 67 and $72 \mathrm{MPa}$ while the 28-day compressive strength values were between 85 and $102 \mathrm{MPa}$. It could be easily seen that the highest compressive strength values were procured in the plain SCC mixtures at both ages. The reduction percentages in the 7-day compressive strength due to basalt fiber addition were about 2.4, 4.8, and 5.9 for the basalt fiber volume fraction values of $0.25,0.50$, and $1.00 \%$, respectively; while the decreasing rate in the 28-day compressive strength by the basalt fiber utilization were about $7.3,10.9$, and $16.1 \%$ for the basalt fiber volume fractions of $0.25,0.50$, and $1.00 \%$, respectively.

The effects of basalt fiber volume fraction on the elastic modulus of SCCs have been indicated in Fig. 16. It can be easily said that no significant effect of basalt fiber on the elastic modulus was observed since there is a fluctuating in the elastic modulus with the increasing of the basalt fiber volume fraction. Namely, there is no decreasing or increasing trend for elastic modulus concerning basalt fiber volume fraction increasing. The SCCs produced with the basalt fiber volume fraction of $0.50 \%$ and $1.0 \%$ have the elastic modulus of $36.4 \mathrm{GPa}$ and $31.5 \mathrm{GPa}$, respectively. 
The Poisson's ratios measured for the SCC at different ambient temperatures have been submitted in Fig. 17. The results indicated there was an increasing trend for the SCC up to the basalt fiber volume fraction of $0.50 \%$, but, after this volume fraction, the decreasing in the Poisson's ratio was observed. This is attributed to increasing of rigidity of this material with increasing fiber content.

The tensile strength of the concrete was measured in present work on the basis of splitting tensile and flexural strength tests to achieve supportive information about the influence of basalt fiber content on the tensile behavior of the SCC. The results obtained from the splitting tensile strength test have been indicated in Fig. 18. It is noticed that the splitting tensile strength of the SCCs was increased by $0.25 \%$ basalt fiber addition, however, there was a decreasing trend in the splitting tensile strength after $0.25 \%$ basalt fiber volume fraction. This may be caused by the decreasing of the self compactibility of the concrete with higher basalt fiber incorporation. Another reason may be the coagulation of basalt fiber particles at higher volume fraction. The highest splitting tensile strength value of 7.32 $\mathrm{MPa}$ was achieved at the SCC manufactured with $0.25 \%$ basalt fiber.

The other test performed to evaluate the tensile behavior of the SCC mixtures is flexural strength test. The outcomes obtained from this test regarding the basalt fiber volume fraction is demonstrated in Fig. 19. According to the test result, it can be expressed that basalt fiber utilization enhanced the flexural strength of the SCC; where the highest flexural strength value of 8.91 $\mathrm{MPa}$ was attained in the SCC mixture manufactured with $1.00 \%$ basalt fiber whilst the lowest value of 8.24 MPa was procured in the plain SCC mixture. The flexural strength was increased as much as $8.1 \%$ when $1.00 \%$ basalt fiber was introduced. The splitting tensile and flexural strength values of the SCCs at each basalt fiber content were comparatively indicated and it can be clearly comprehended that the flexural strength of the SCC is higher than the splitting tensile strength of the SCC mixtures.

\subsection{Permeability Properties of SCC}

In order to show the effect of the basalt fibers utilization and their content in the SCC production on the permeability properties, the sorptivity index of the SCC mixtures manufactured in this study were determined. The sorptivity index values, which were given as sorptivity coefficients, versus basalt fiber volume fraction have been submitted in Fig. 20. The results indicated that the greatest capillary water suction was observed in the plain SCC mixture, since its sorptivity coefficient value is the highest. The test result indicated that the rising of the basalt fiber volume fraction from 0.25 to $0.50 \%$ resulted in the increasing of the sorptivity index value, namely resulted in the increasing of the capillary water suction. However, the sorptivity index value decreased by the rising of the basalt fiber volume fraction from 0.50 to $1.00 \%$. The decreasing of the sorptivity index values, by the basalt fiber addition, is attributed to the void filling ability of the basalt fiber since the particle sizes of basalt fiber are in the microscale.

The water penetration depth values versus basalt fiber volume fraction have been graphically presented in Fig. 21. Basalt fiber utilization at the content of $0.25 \%$ resulted in the decreasing of the water penetration depth about $6 \%$ whereas the basalt fibers contents of 0.50 and $1.00 \%$ caused increasing of the water penetration depth as much as 54.7 and $15.0 \%$, respectively.

Fig. 22 indicates the change in the resistance of the SCCs to chloride ion penetration in terms of total charge passed versus basalt fiber volume fraction. 
According to current test measurements, it can be said that SCCs chloride ion penetrability is negligible since all values measured in this study are less than $100 \mathrm{C}$ according to ASTM C1202 [49].

\section{Conclusions}

Present work is devoted to investigate the properties of fresh and hardened self-compacted concrete with basalt fibers; the effect of basalt fiber content on the mechanical properties of SCC samples was taken into account. Based on current experimental measurements, the following conclusions can be drawn:

- Basalt fibers volume fraction of more than $0.25 \%$ has remarkable role in decreasing the folwability of SCC and delaying its flow time.

- Seven days aged samples of SCC with basalt fibers provides $75 \%$ of full compressive strength which attained at 28 days.

- Compressive strength of basalt fibers SCC reduces dramatically and systematically due to using fibers content of $0 \%-1.0 \%$ with reduction percentage of $22.4 \%$ which is attributed to lightening in SCC weight with introducing of fibers.

- There is no significant effect of basalt fiber on the elastic modulus of SCC.

- Poisson's ratio of SCC is widely decreased with adding more than $0.5 \%$ fibers content.

- Splitting and flexural strengths of SCC are improved with utilizing more than $0.25 \%$ of basalt fibers.

- SCC with basalt fibers is characterized by its lowest sorptivity index due to the void filling ability of the micro-scale basalt fibers; where $0.25 \%$ content of basalt fibers increases water penetration depth of SCC in high extent.

- SCC can be considered as negligible chloride ion penetrability composite.

\section{References}

1. Wang X., He J., Mosallam A. S., Li Ch., Xin H. The effects of fiber length and volume on material properties and crack resistance of basalt fiber reinforced concrete (BFRC), Advances in Materials Science and Engineering, Volume 2019.

2. S. T. Tassew and A. S. Lubell, "Mechanical properties of glass fiber reinforced ceramic concrete," Construction and Building Materials, vol. 51, pp. 215-224, 2014. [3] F. U. A. Shaikh, "Review of mechanical properties of short fibre reinforced geopolymer composites," Construction and Building Materials, vol. 43, pp. 37-49, 2013.

3. C. Jiang, K. Fan, F. Wu, and D. Chen, "Experimental study on the mechanical properties and microstructure of chopped basalt fibre reinforced concrete," Materials \& Design, vol. 58, pp. 187-193, 2014.

4. A. B. Kizilkanat, N. Kabay, V. Aky"unc"u, S. Chowdhury, and A. H. Akça, "Mechanical properties and fracture behavior of basalt and glass fiber reinforced concrete: an experimental study," Construction and Building Materials, vol. 100, pp. 218-224, 2015.

5. T. Uygunoglu, "Investigation of microstructure and flexural " behavior of steel fiber reinforced concrete," Materials and Structures, vol. 41, no. 8, pp. 14411449, 2008.

6. [7] E. G"uneyisi, M. Geso glu, A. O. M. Akoi, and K.

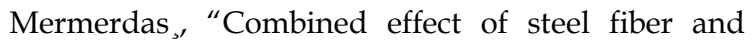
metakaolin incorporation on mechanical properties of concrete," Composites Part B: Engineering, vol. 56, pp. 83-91, 2014.

7. J. 1omas and A. Ramaswamy, "Mechanical properties of steel fiber-reinforced concrete," Journal of Materials in Civil Engineering, vol. 19, no. 5, pp. 385-392, 2007.

8. M. G. Alberti, A. Enfedaque, and J. C. Galvez, "Fibre rein- ' forced concrete with a combination of polyolefin and steelhooked fibres," Composite Structures, vol. 171, pp. 317-325, 2017. 
9. [10] S. Iqbal, A. Ali, K. Holschemacher, and T. A. Bier, "Mechanical properties of steel fiber reinforced high strength lightweight self-compacting concrete (SHLSCC)," Construction and Building Materials, vol. 98, pp. 325-333, 2015.

10. K. Hannawi, H. Bian, W. Prince-Agbodjan, and B. Raghavan, "Effect of different types of fibers on the microstructure and the mechanical behavior of ultrahigh Performance Fiber Reinforced Concretes," Composites Part B: Engineering, vol. 86, pp. 214-220, 2016.

11. M. L. Santarelli, F. Sbardella, M. Zuena, J. Tirillo, and

F. Sarasini, "Basalt fiber reinforced natural hydraulic lime mortars: a potential bio-based material for restoration," Materials \& Design, vol. 63, pp. 398-406, 2014.

12. N. Banthia and M. Sappakittipakorn, "Toughness enhancement in steel fiber reinforced concrete through fiber hybridization," Cement and Concrete Research, vol. 37, no. 9, pp. 1366-1372, 2007.

13. Y. Sahin and F. Koksal, "1e influences of matrix and steel " fibre tensile strengths on the fracture energy of high-strength concrete," Construction and Building Materials, vol. 25, no. 4, pp. 1801-1806, 2011.

14. J. Michels, R. Christen, and D. Waldmann, "Experimental and numerical investigation on postcracking behavior of steel fiber reinforced concrete," Engineering Fracture Mechanics, vol. 98, pp. 326-349, 2013.

15. A. Mosallam, J. Slenk, and J. Kreiner, “Assessment of residual tensile strength of carbon/epoxy composites subjected to lowenergy impact," Journal of Aerospace Engineering, vol. 21, no. 4, pp. 249-258, 2008.

16. Jiao H., Wu Y., Chen X., Yang Y. Flexural toughness of basalt fibre-reinforced shotcrete and industrialscale testing. Advances in Materials Science and Engineering Volume 2019.

17. Singh S. Kaushik P. S. K., Fatigue strength of steel fibre reinforced concrete in flexure," Cement and Concrete Composites, vol. 25, no. 7, pp. 779-786,
2003.

18. [19] De'ak T., Czig'any T., Chemical composition and mechanical properties of basalt and glass fibers: a comparison, Textile Research Journal, vol. 79, no. 7, pp. 645-651, 2009.

19. Q. Ma, Z. Yang, Y. Gu, M. Li, S. Wang, and Z. Zhang, Permeabilities along fiber direction of ramie bundles and through-thickness of ramie fabric stack for liquid composite molding, Journal of Reinforced Plastics and Composites, vol. 36, no. 1, pp. 40-52, 2017.

20. J. Sun, X. Yao, X. Tian, C. Jingliang, and W. Yi, "Damage characteristics of CFRP laminates subjected to multiple lightning current strike," Applied Composite Materials, vol. 26, no. 3, pp. 745762, 2019.

21. V. Lopresto, C. Leone, and I. De Iorio, "Mechanical characterisation of basalt fibre reinforced plastic," Composites Part B: Engineering, vol. 42, no. 4, pp. 717-723, 2011.

22. P. Davies and W. Verbouwe, "Evaluation of basalt fibre composites for marine applications," Applied Composite Materials, vol. 25, no. 2, pp. 299-308, 2018.

23. C. H. Jiang, T. J. McCarthy, D. Chen, and Q. Q. Dong, "Influence of basalt fiber on performance of cement mortar," Key Engineering Materials, vol. 426427, pp. 93-96, 2010.

24. T. M. Borhan and C. G. Bailey, "Structural behaviour of basalt fibre reinforced glass concrete slabs," Materials and Structures, vol. 47, no. 1-2, pp. 77-87, 2014.

25. T. M. Borhan and C. G. Bailey, "Modelling basalt fibre reinforced glass concrete slabs at ambient and elevated temperatures," Materials and Structures, vol. 47, no. 6, pp. 999-1009, 2014.

26. Z. Kan and Y. Li, "Analysis on mechanical properties and durability of the chopped basalt fiber reinforced concrete," Advanced Materials Research, vol. 598, pp. 627-630, 2012.

27. H. L. Wang and Y. H. Zhong, "Research status and 
proposals of basalt fiber reinforced concrete," Advanced Materials Research, vol. 834, pp. 730-737, 2014.

28. Ayub T., Shafiq N., Nuruddin M. F. Effect of chopped basalt fibers on the mechanical properties and microstructure of high performance fiber reinforced concrete, Advances in Materials Science and Engineering, Volume 2014.

29. J. Branston, S. Das, S. Y. Kenno, and C. Taylor, "Mechanical behaviour of basalt fibre reinforced concrete," Construction and Building Materials, vol. 124, pp. 878-886, 2016.

30. Q. Fu, D. Niu, J. Zhang et al., "Dynamic compressive mechanical behaviour and modelling of basaltpolypropylene fibre-reinforced concrete," Archives of Civil and Mechanical Engineering, vol. 18, no. 3, pp. 914-927, 2018.

31. T. M. Borhan, Thermal and mechanical properties of basalt fibre reinforced concrete, World Academy of Science, Engineering and Technology, vol. 7, pp. 712-715, 2013.

32. A. Zeynep and O. Mustafa, The properties of chopped basalt fibre reinforced self-compacting concrete, Construction and Building Materials, vol. 186, pp. 678-685, 2018.

33. J. Ma, X. Qiu, L. Cheng, and Y. Wang, “Experimental research on the fundamental mechanical properties of presoaked basalt fiber concrete," in CICE 2010@e 5th International Conference on FRP Composites in Civil Engineering, pp. 1-4, Beijing, China, September 2010.

34. M. E. Arslan, "Effects of basalt and glass chopped fibers addition on fracture energy and mechanical properties of ordinary concrete: CMOD measurement," Construction and Building Materials, vol. 114, pp. 383-391, 2016.

35. Y. Zheng, P. Zhang, Y. Cai, Z. Jin, and E. Moshtagh, "Cracking resistance and mechanical properties of basalt fibers reinforced cement-stabilized macadam," Composites Part B: Engineering, vol. 165, pp. 312$334,2019$.
36. W. Li and J. Xu, "Mechanical properties of basalt fiber reinforced geopolymeric concrete under impact loading," Materials Science and Engineering: A, vol. 505, no. 1-2, pp. 178-186, 2009.

37. M. El-Gelani, C. M. High, S. H. Rizkalla, and E. A. Abdalla, "Effects of basalt fibres on mechanical properties of concrete," MATEC Web of Conferences, vol. 149, Article ID 01028, 2018.

38. [39] ASTM C127-15, Standard Test Method for Relative Density (Specific Gravity) and Absorption of Coarse Aggregate, ASTM International, West Conshohocken, PA, 2015.

39. [40] ASTM C128-15, Standard Test Method for Relative Density (Specific Gravity) and Absorption of Fine Aggregate, ASTM International, West Conshohocken, PA, 2015.

40. [41] ASTM C136 / C136M-14, Standard Test Method for Sieve Analysis of Fine and Coarse Aggregates, ASTM International, West Conshohocken, PA, 2014.

41. [42] EFNARC (2005) Specification and guidelines for self-compacting concrete, http://www.efnarc.org

42. ASTM C1621 / C1621M-17 (2017) Standard Test Method for Passing Ability of Self-Consolidating Concrete by J-Ring, ASTM International, West Conshohocken, PA.

43. ASTM C39 / C39M-18 (2018) Standard Test Method for Compressive Strength of Cylindrical Concrete Specimens, ASTM International, West Conshohocken, PA,

44. ASTM C469 / C469M-14 (2014) Standard Test Method for Static Modulus of Elasticity and Poisson's Ratio of Concrete in Compression, ASTM International, West Conshohocken, PA,

45. ASTM C496 / C496M-17 (2017) Standard Test Method for Splitting Tensile Strength of Cylindrical Concrete Specimens, ASTM International, West Conshohocken, PA.

46. ASTM C78 / C78M-18 (2018) Standard Test Method for Flexural Strength of Concrete (Using Simple Beam with Third-Point Loading), ASTM International, West Conshohocken, PA. 
47. TS-EN 12390-8 (2002) Testing Hardened Concrete-

Part 8: Depth of Penetration of Water under Pressure. Institute of Turkish Standards, Ankara, Turkey.

48. ASTM C1202-19 (2019) Standard Test Method for Electrical Indication of Concrete's Ability to Resist Chloride Ion Penetration, ASTM International, West Conshohocken, PA. 
Table 1: Sieve analysis and physical properties of river sand and crushed coarse aggregates

\begin{tabular}{ccc}
\hline Sieve size (mm) & $\begin{array}{c}\text { River sand } \\
(\text { passing \%) }\end{array}$ & $\begin{array}{c}\text { Crushed coarse aggregate } \\
\text { (passing \%) }\end{array}$ \\
\hline 16 & 100 & 100 \\
8 & 100 & 47 \\
4 & 100 & 11 \\
2 & 86 & 2 \\
1 & 67 & 0 \\
0.5 & 43 & 0 \\
0.25 & 22 & 0 \\
\hline Fineness modulus & 1.82 & 5.40 \\
Specific gravity & 2.61 & 2.66 \\
\hline
\end{tabular}

Table 2: Physical properties of basalt fiber

\begin{tabular}{lll}
\hline Properties & Fiber MF Concrete & Unit \\
\hline Fiber length & 24 & $\mathrm{~mm}$ \\
Fiber diameter & $16 \pm 2$ & $\mu \mathrm{m}$ \\
Density & 2.80 & $\mathrm{~g} / \mathrm{cm}^{3}$ \\
Elastic modulus & 89 & $\mathrm{GPa}$ \\
Melting temperature & 1450 & ${ }^{\circ} \mathrm{C}$ \\
Break extension & 3.15 & $\%$ \\
\hline Raw materials & Basalt & \\
Color & Dark grey/Smoked & \\
\hline \hline
\end{tabular}

Table 3: Properties of present superplasticizer

\begin{tabular}{ll}
\hline Properties & Fiber MF Concrete \\
\hline Form & Liquid \\
Color & Light yellow \\
Specific gravity & $1.05 \pm 0.02$ \\
Water solubility & Soluble \\
Freezing temperature & $-3^{\circ} \mathrm{C}$ \\
\hline \hline
\end{tabular}


Table 4: Detailed mixture proportions for ordinary and self-compacting concretes $\left(\mathrm{kg} / \mathrm{m}^{3}\right)$

\begin{tabular}{lllll}
\hline Mix ID & SCC & SCC25 $^{*}$ & SCC50 & SCC100 \\
\hline Binder content & 570.0 & 570.0 & 570.0 & 570.0 \\
Portland cement & 484.5 & 484.5 & 484.5 & 484.5 \\
Silica fume & 85.5 & 85.5 & 85.5 & 85.5 \\
water-to-binder ratio & 0.30 & 0.30 & 0.30 & 0.30 \\
Water & 171.0 & 171.0 & 171.0 & 171.0 \\
River sand & 936.3 & 936.3 & 936.3 & 936.3 \\
Crushed coarse aggregate & 671.7 & 671.7 & 671.7 & 671.7 \\
Superplasticizer & 5.7 & 11.4 & 17.1 & 22.8 \\
Basalt fiber & - & 7.0 & 14.0 & 28.0 \\
\hline
\end{tabular}

* The number given in the row was used to denote the basalt fiber volume fractions. For instance, SCC25 mixture is the self-compacting concrete mixture manufactured with $0.25 \%$ basalt fiber.

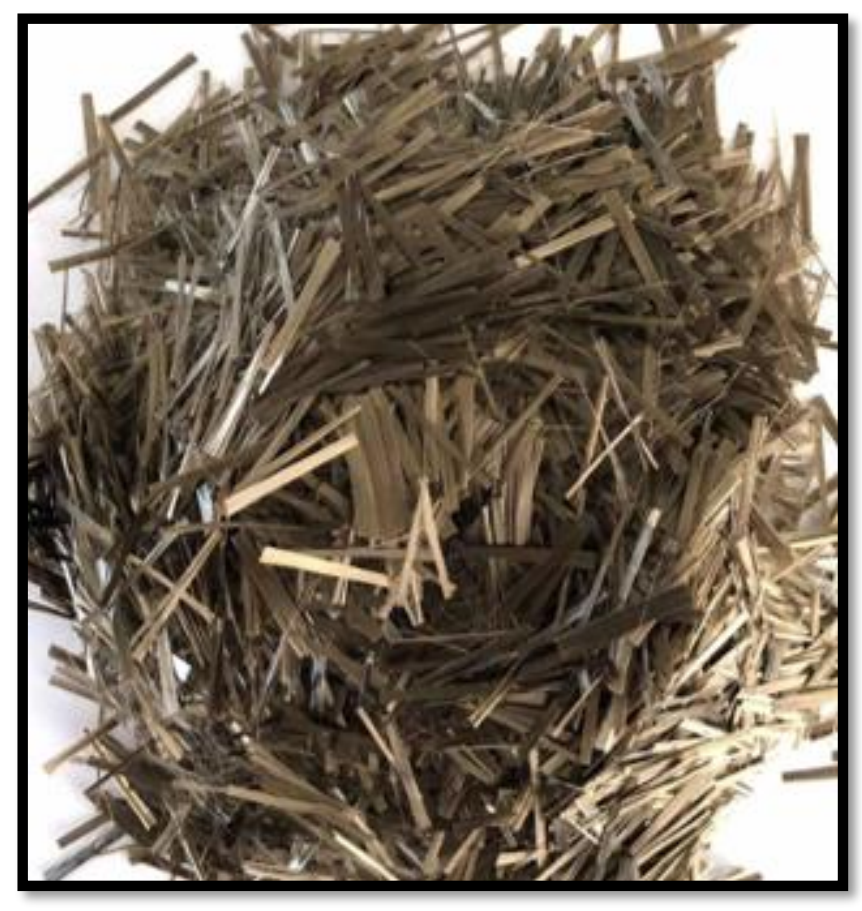

Fig. 1: Photographic view of basalt fiber 


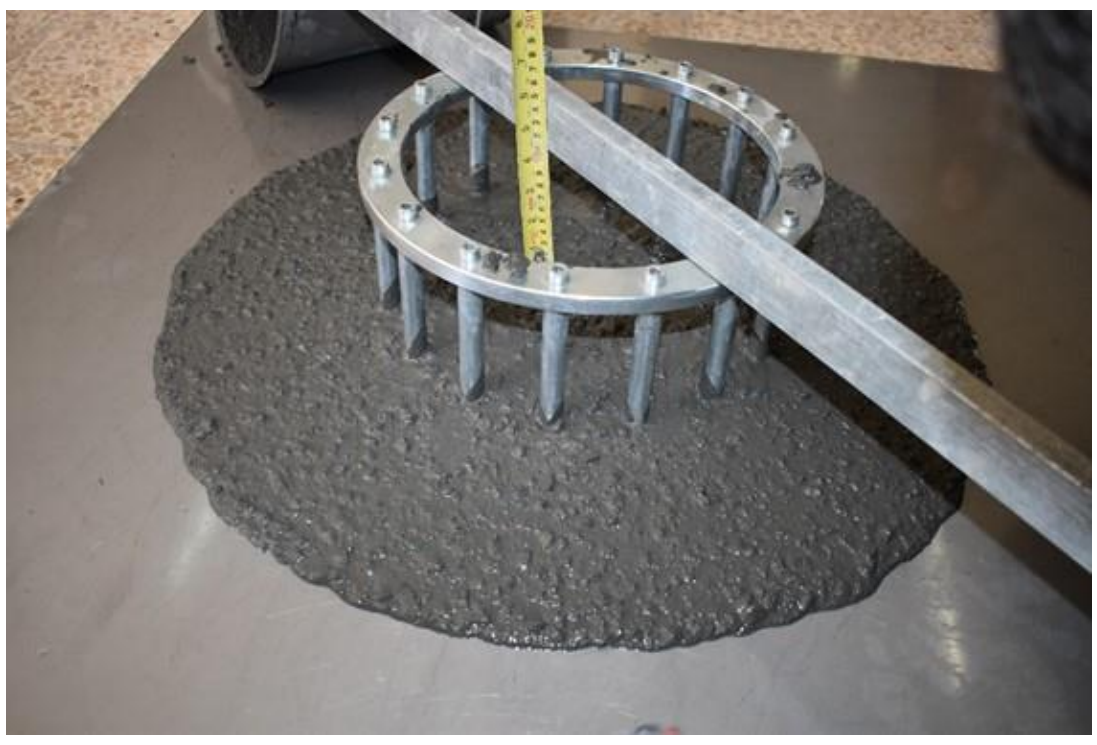

Fig. 2: J-ring test of present SCC

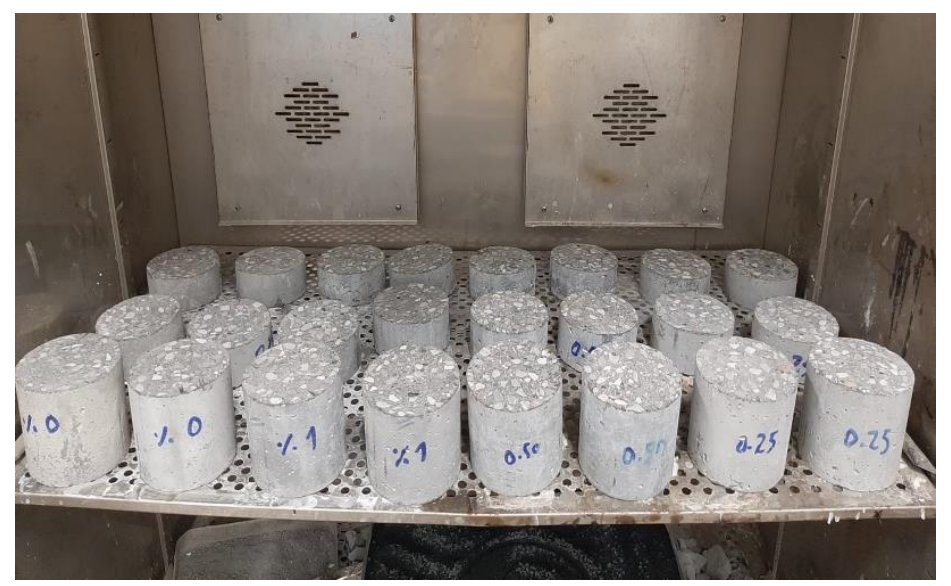

Fig. 3: Sorptivity test SCC samples 


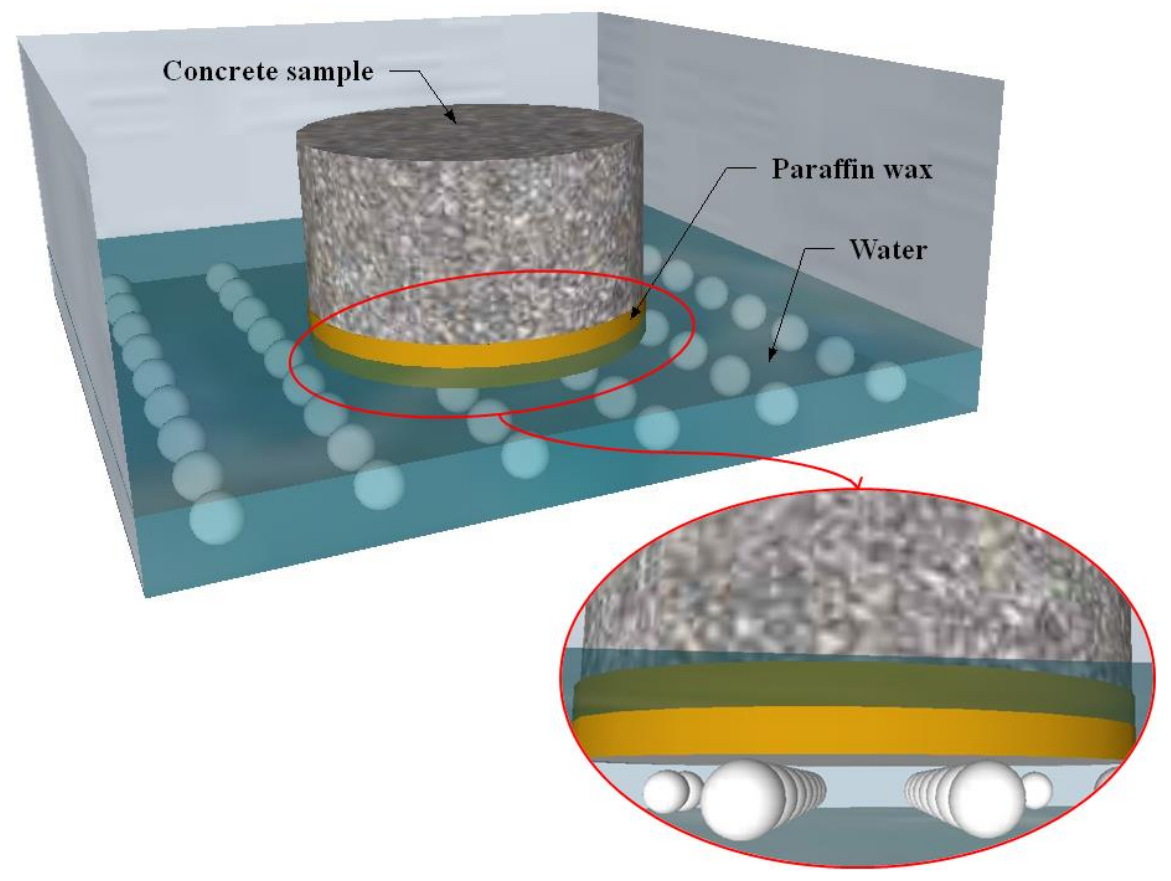

Fig. 4: Sorptivity test set-up simulation

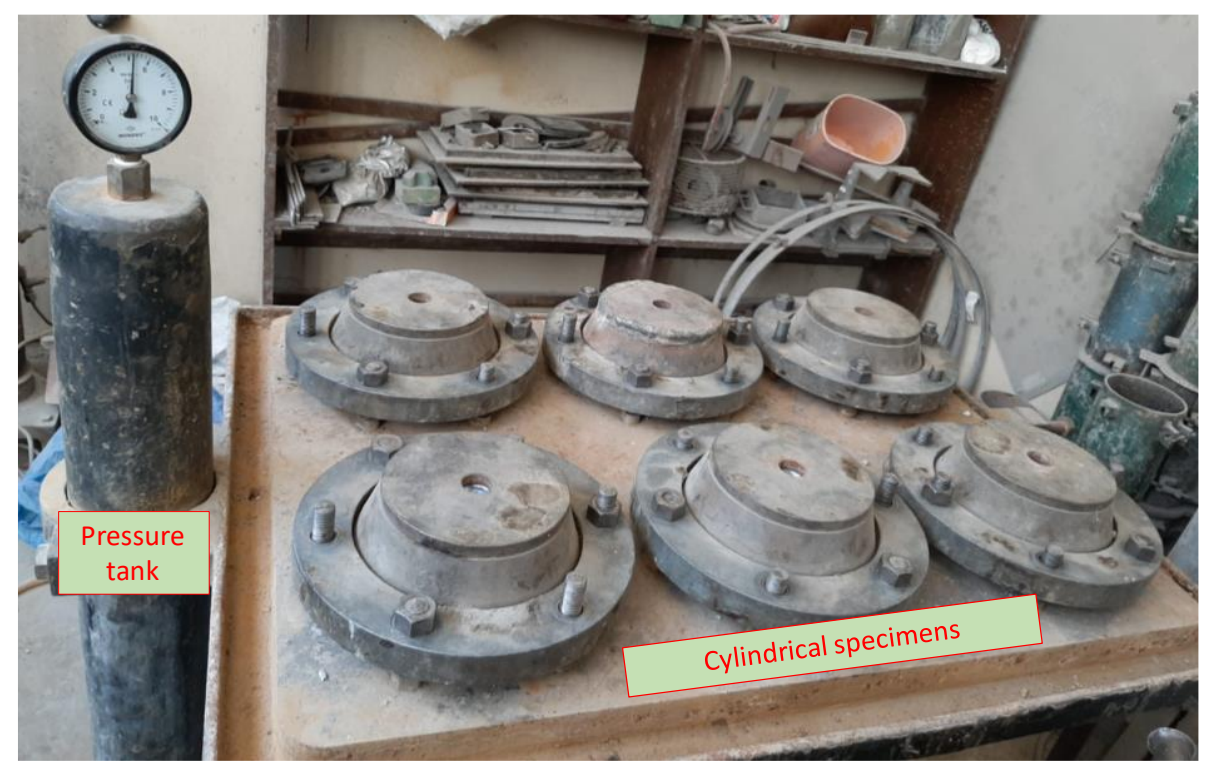

Fig. 5: Water penetration depth test set-up 


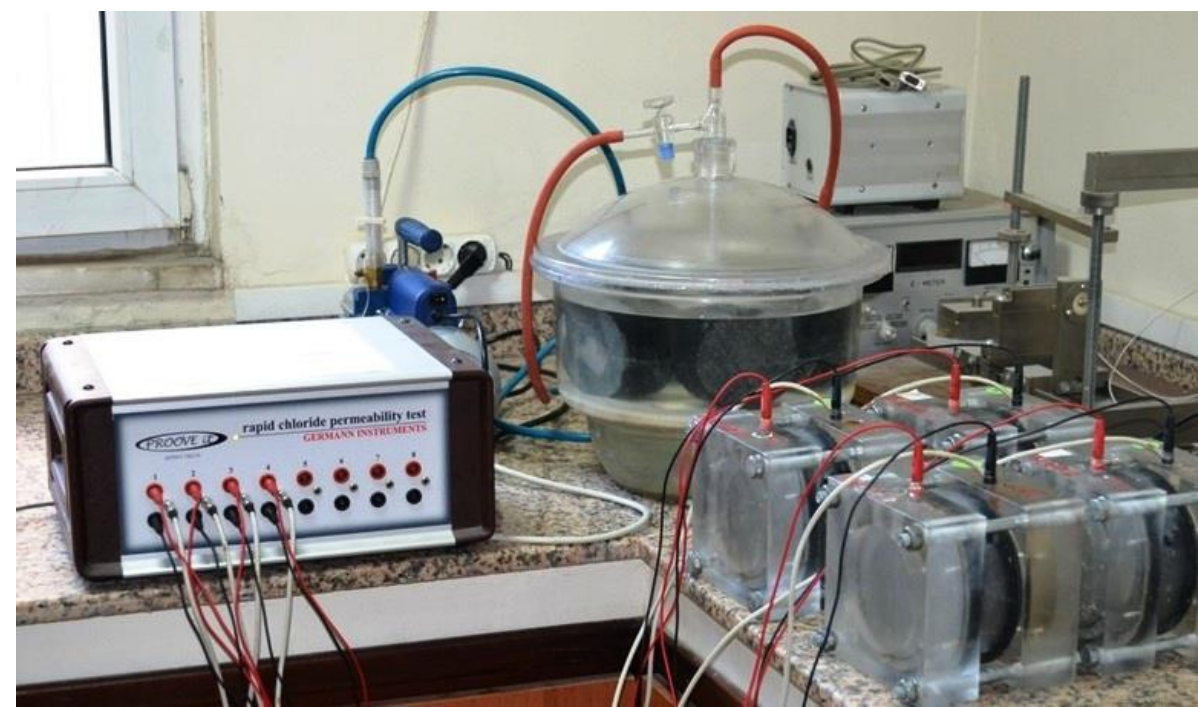

Fig. 6: Rapid chloride permeability test set-up

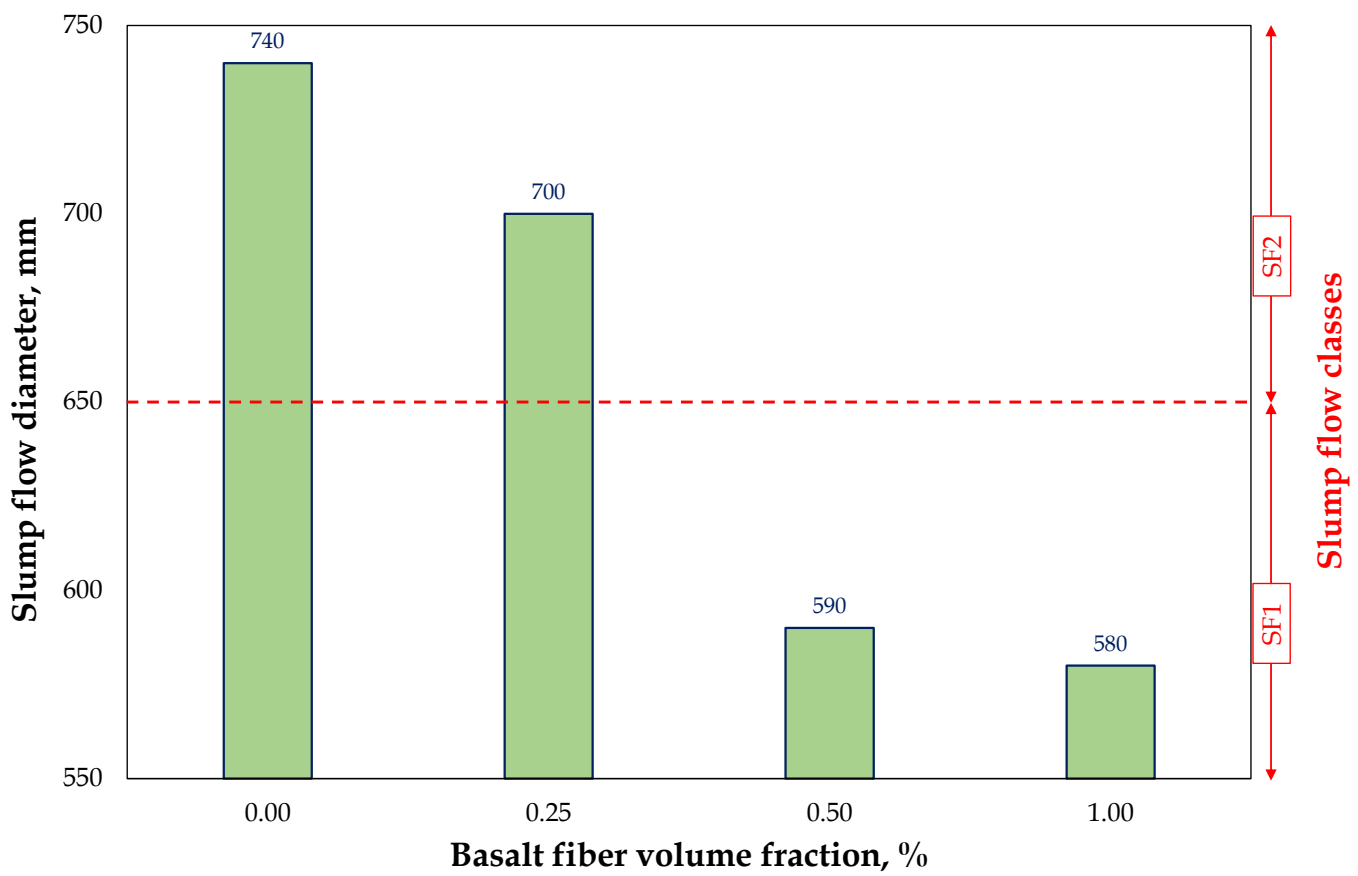

Fig. 7: Variation in slump flow diameter of SCC mixtures concerning basalt fiber volume fraction 


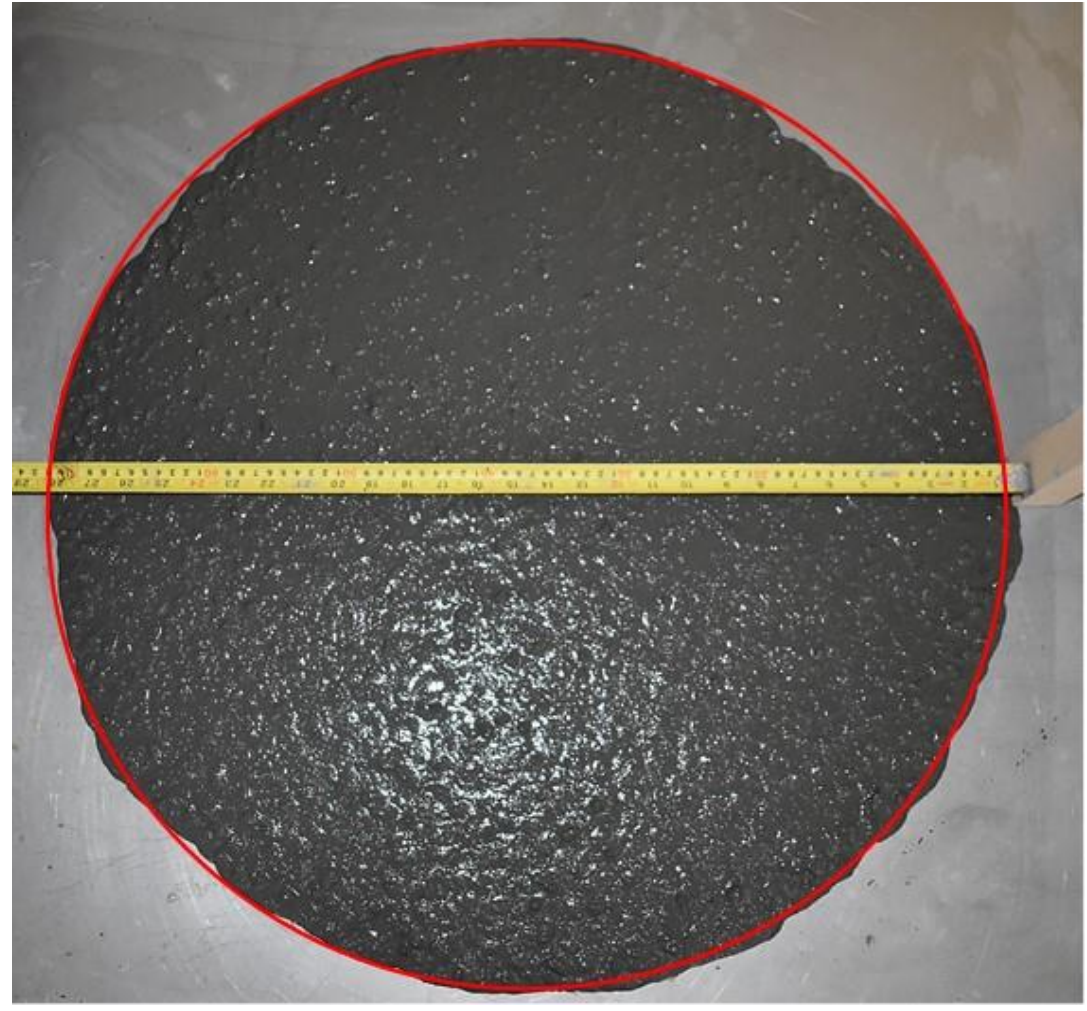

Fig. 8: Photographic view of flowing of SCC mixture with $0.25 \%$ basalt fiber

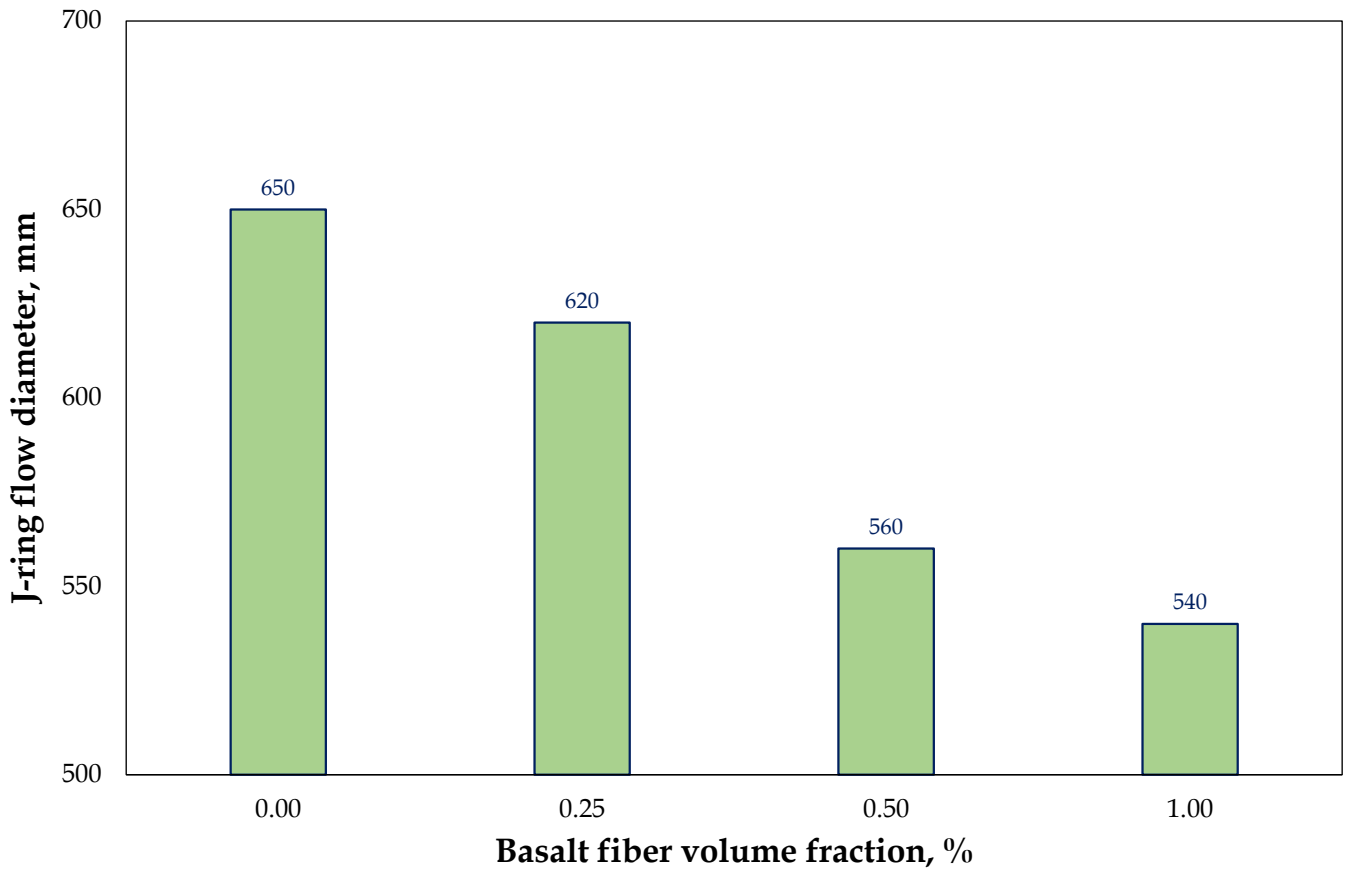

Fig. 9: Variation in J-ring flow diameter of SCC mixtures concerning basalt fiber volume fraction 


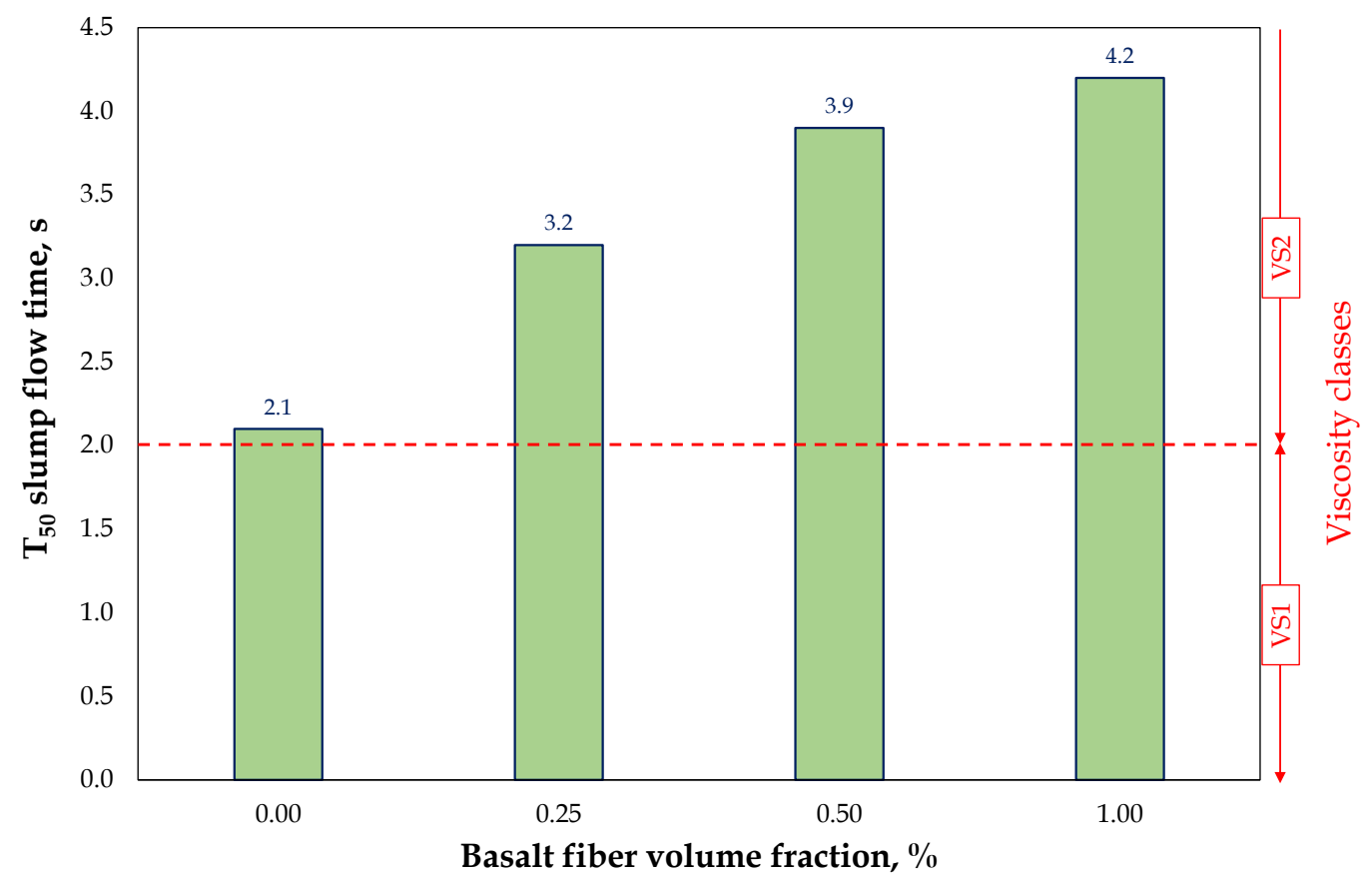

Fig. 10: Variation in T50 slump flow time of SCC mixtures concerning basalt fiber volume fraction

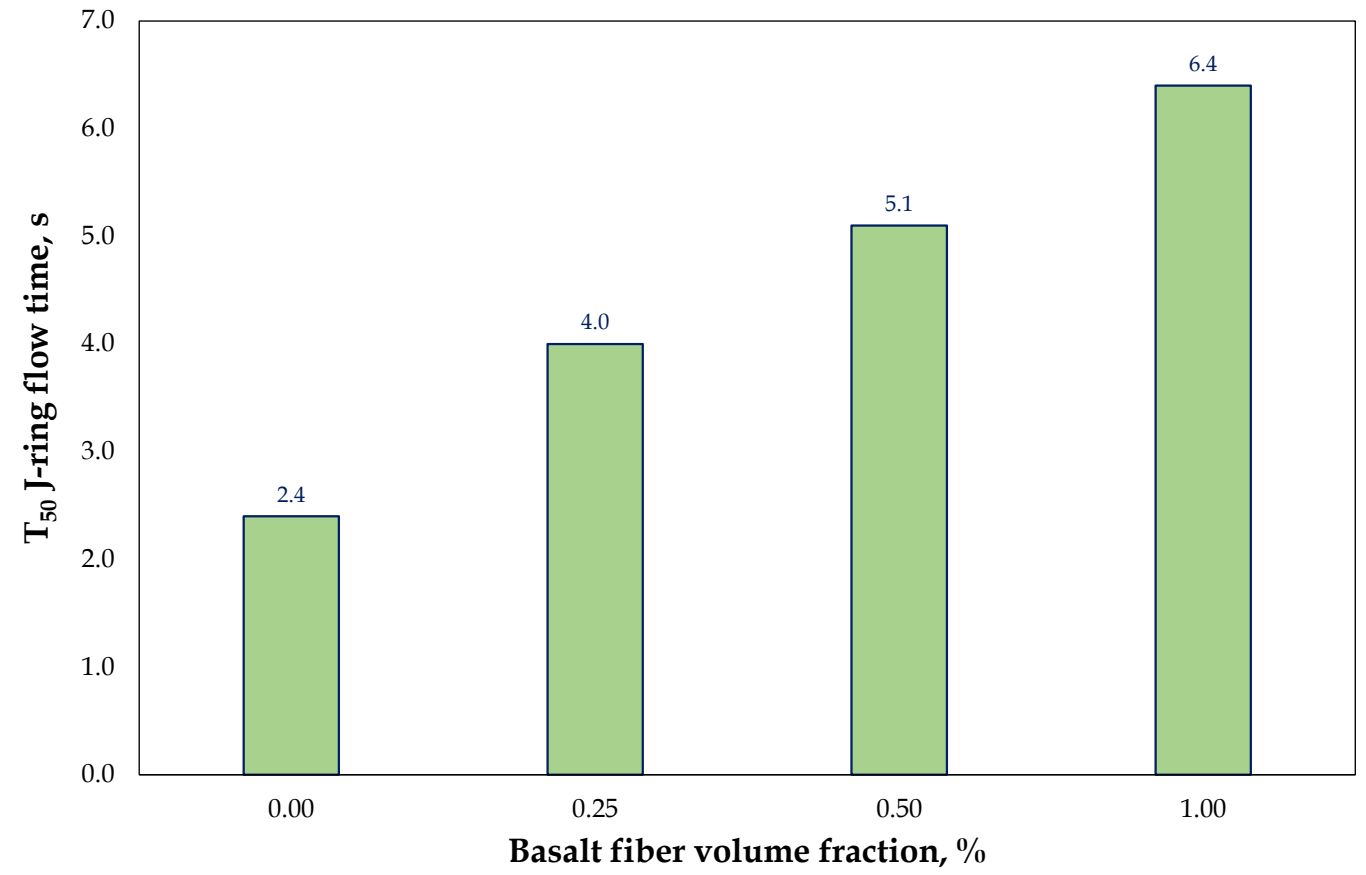

Fig. 11: Variation in T50 J-ring flow time of SCC mixtures concerning basalt fiber volume fraction 


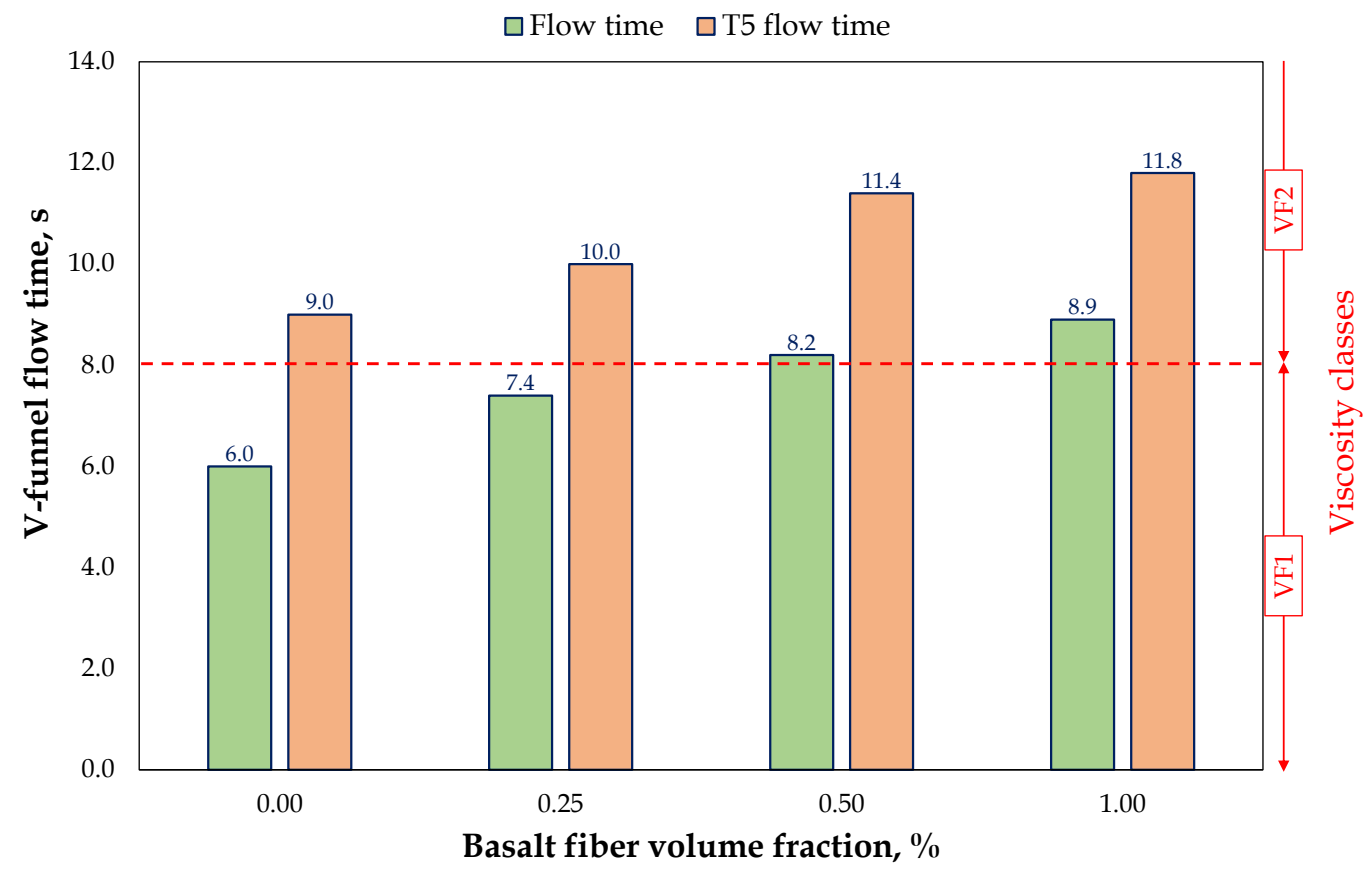

Fig. 12: Variation in V-funnel flow time of SCC mixtures concerning basalt fiber volume fraction

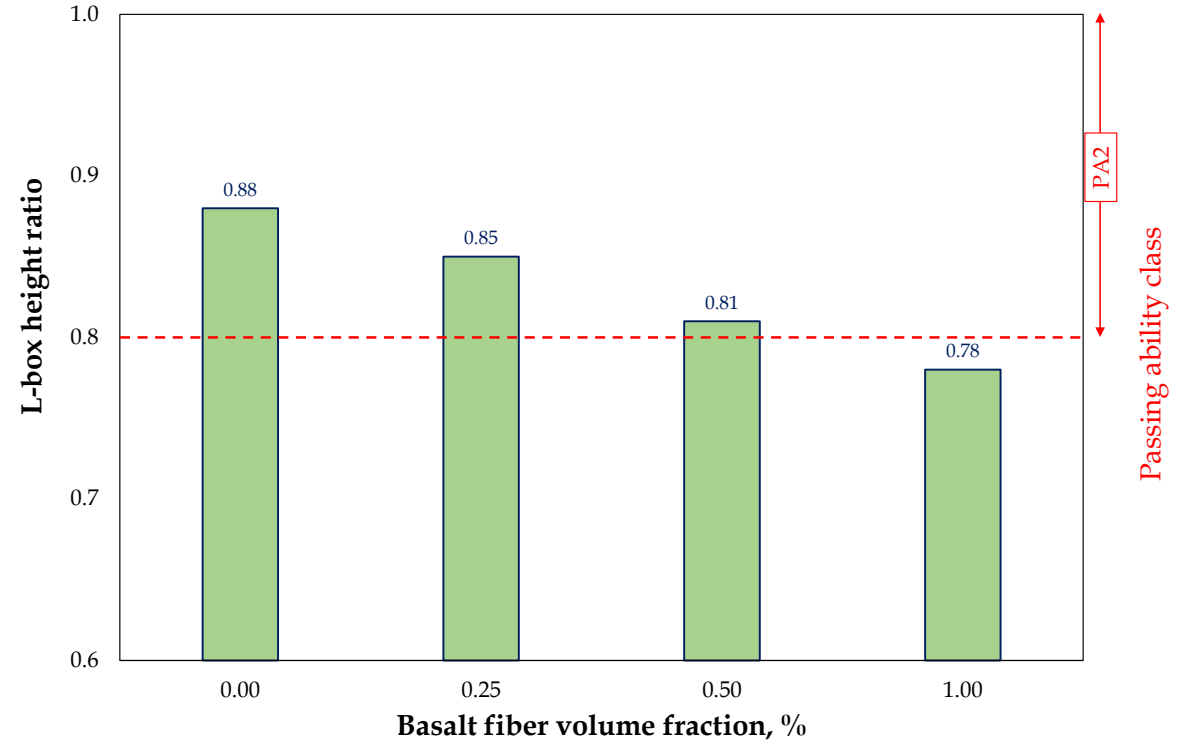

Fig. 13: Variation in L-box height ratio of SCC mixtures concerning basalt fiber volume fraction 


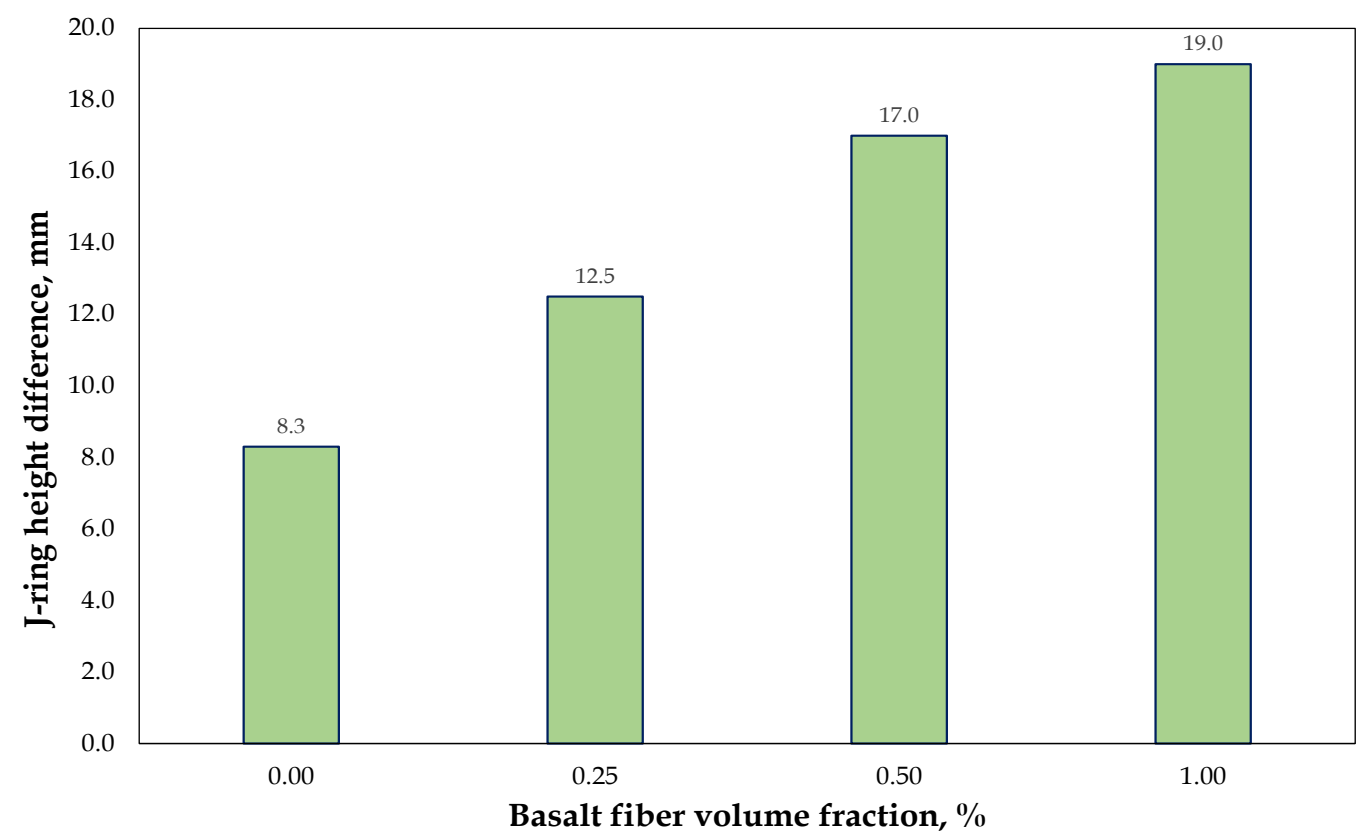

Fig. 14: Variation in J-ring height difference of SCC mixtures concerning basalt fiber volume fraction

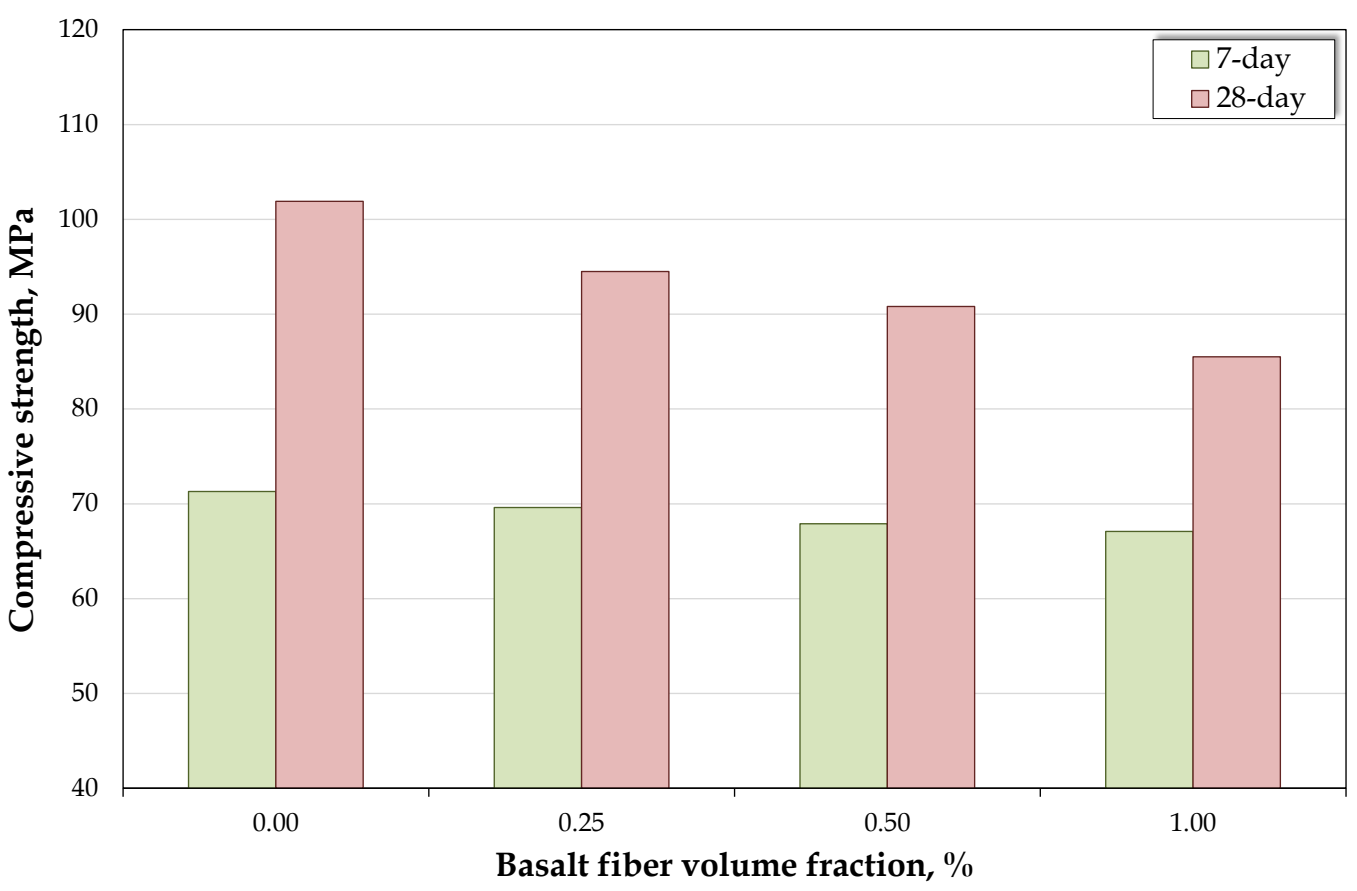

Fig. 15: 7-day and 28-day compressive strength values of SCC mixtures versus basalt fiber volume fraction 


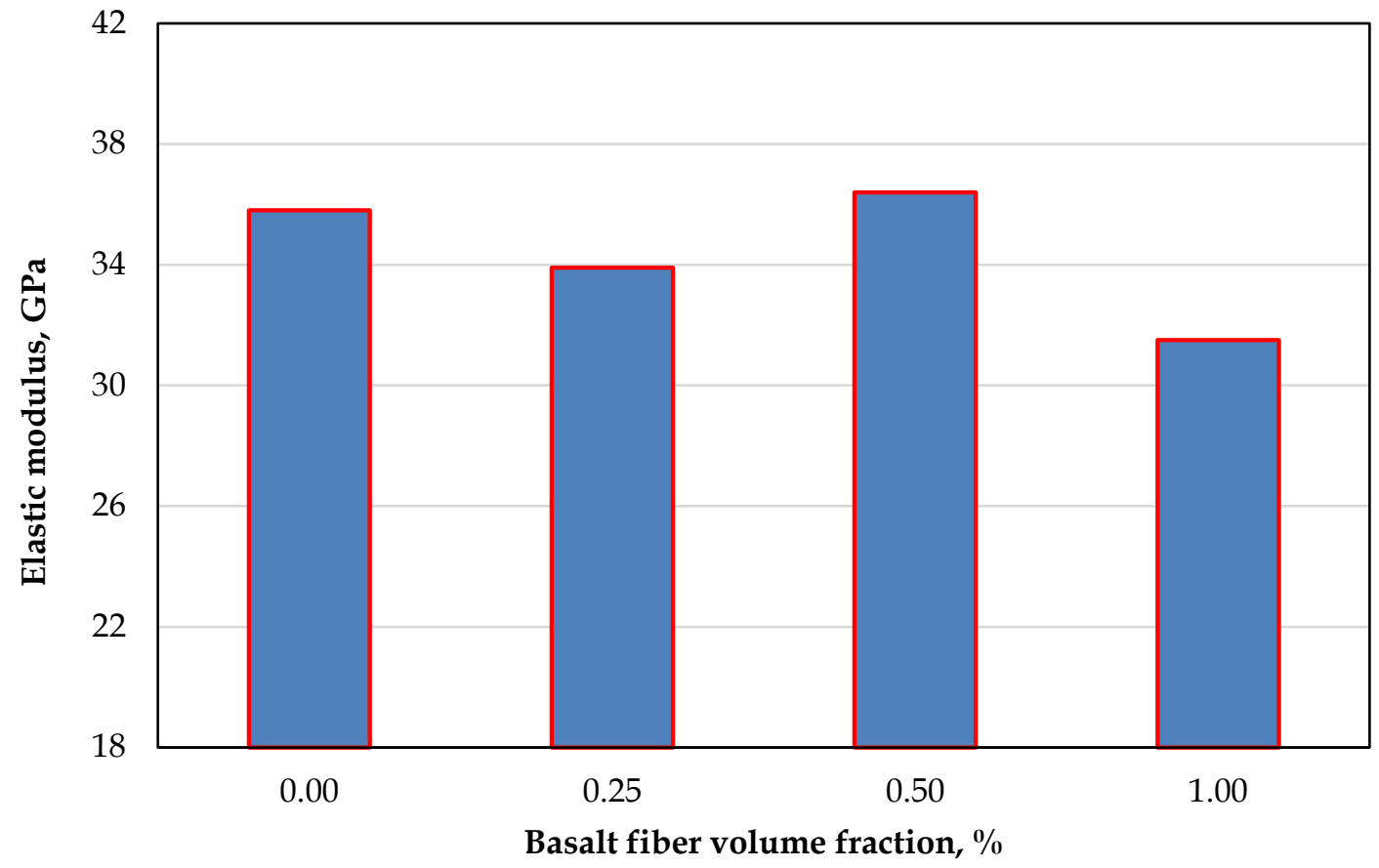

Fig. 16: Variation in elastic modulus of SCC mixtures concerning basalt fiber volume fraction

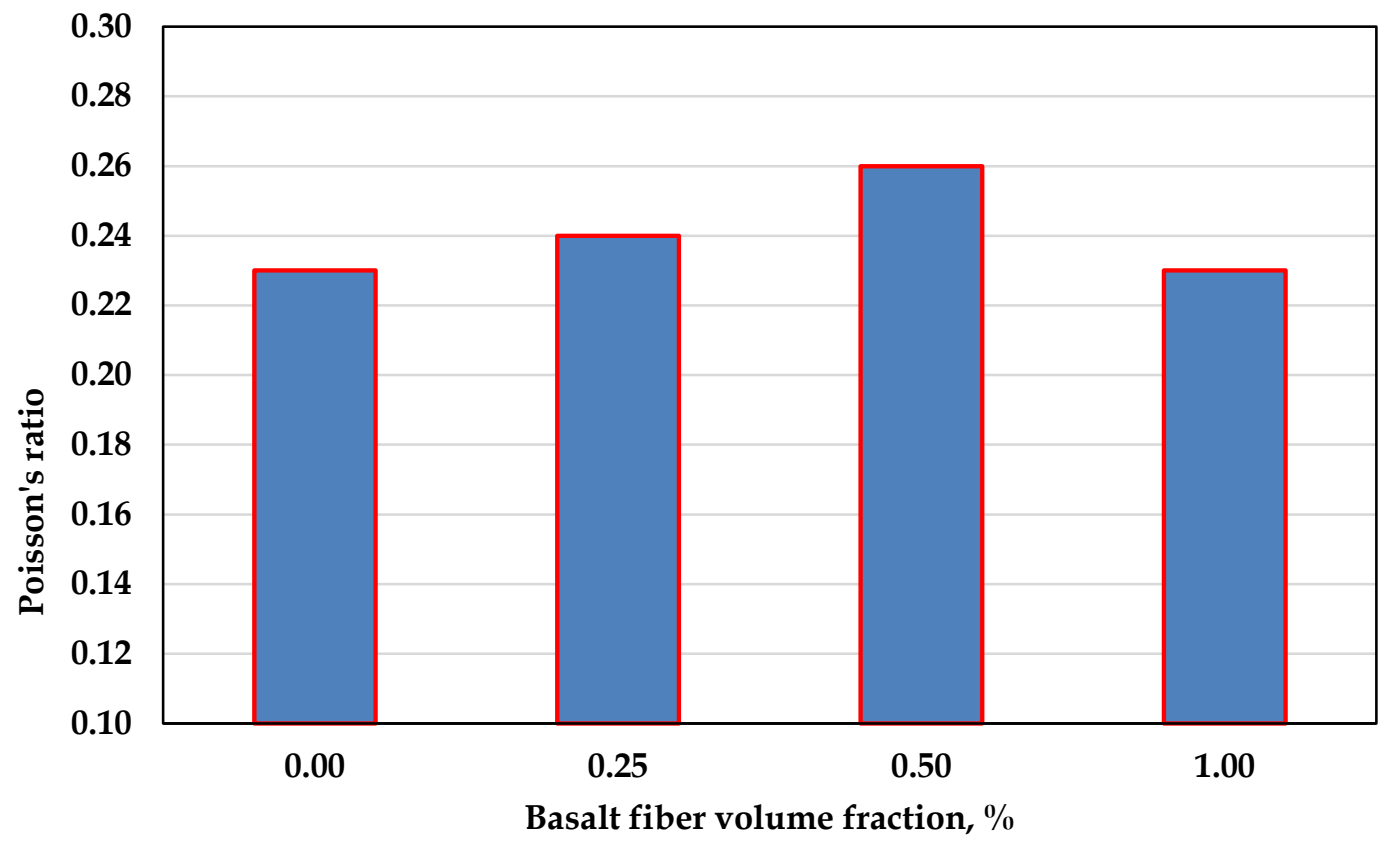

Fig. 17: Variation in Poisson's ratio of SCC mixtures concerning basalt fiber volume fraction and temperature 


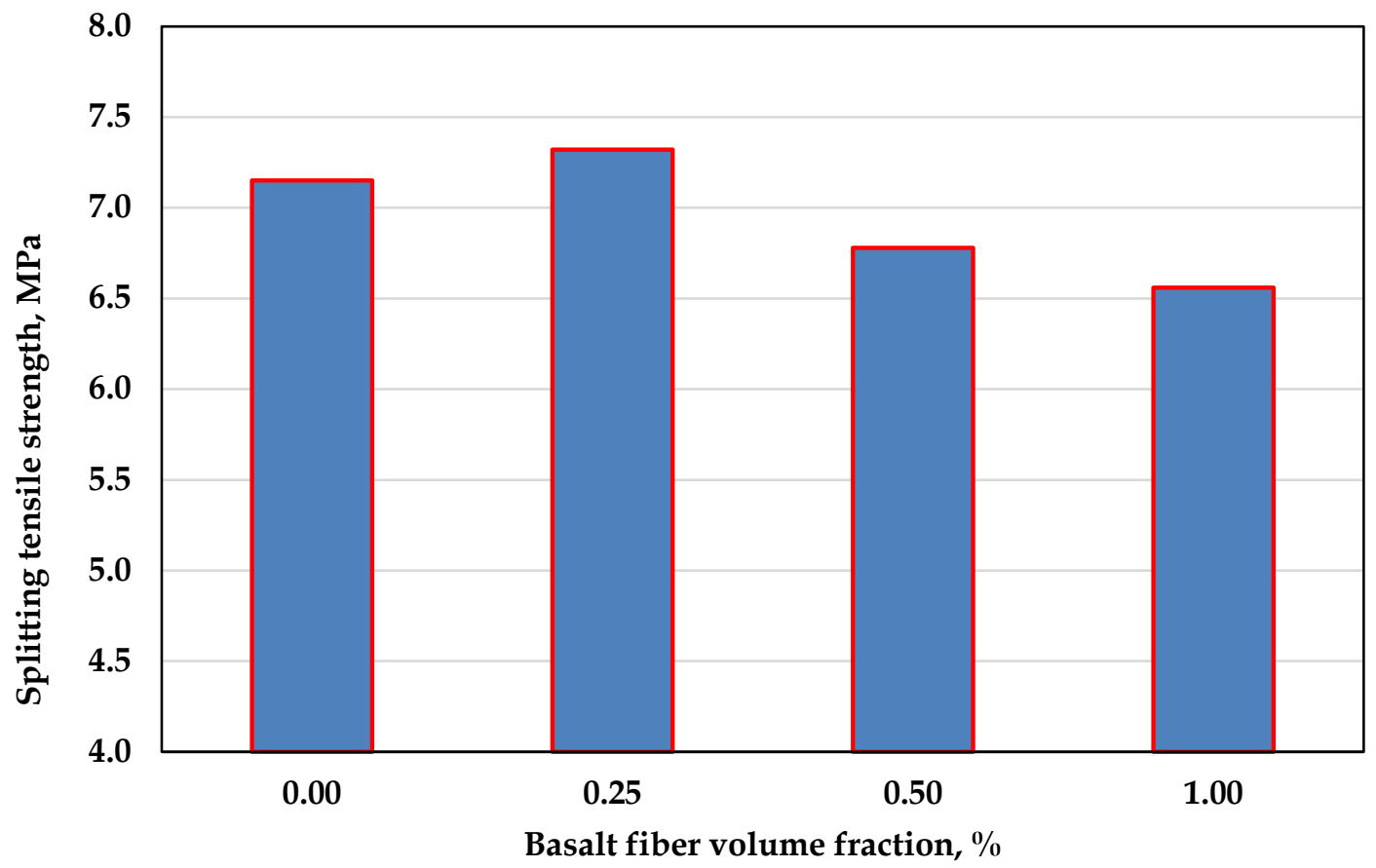

Fig. 18: Splitting tensile strength of SCC with respect to the basalt fiber volume fraction

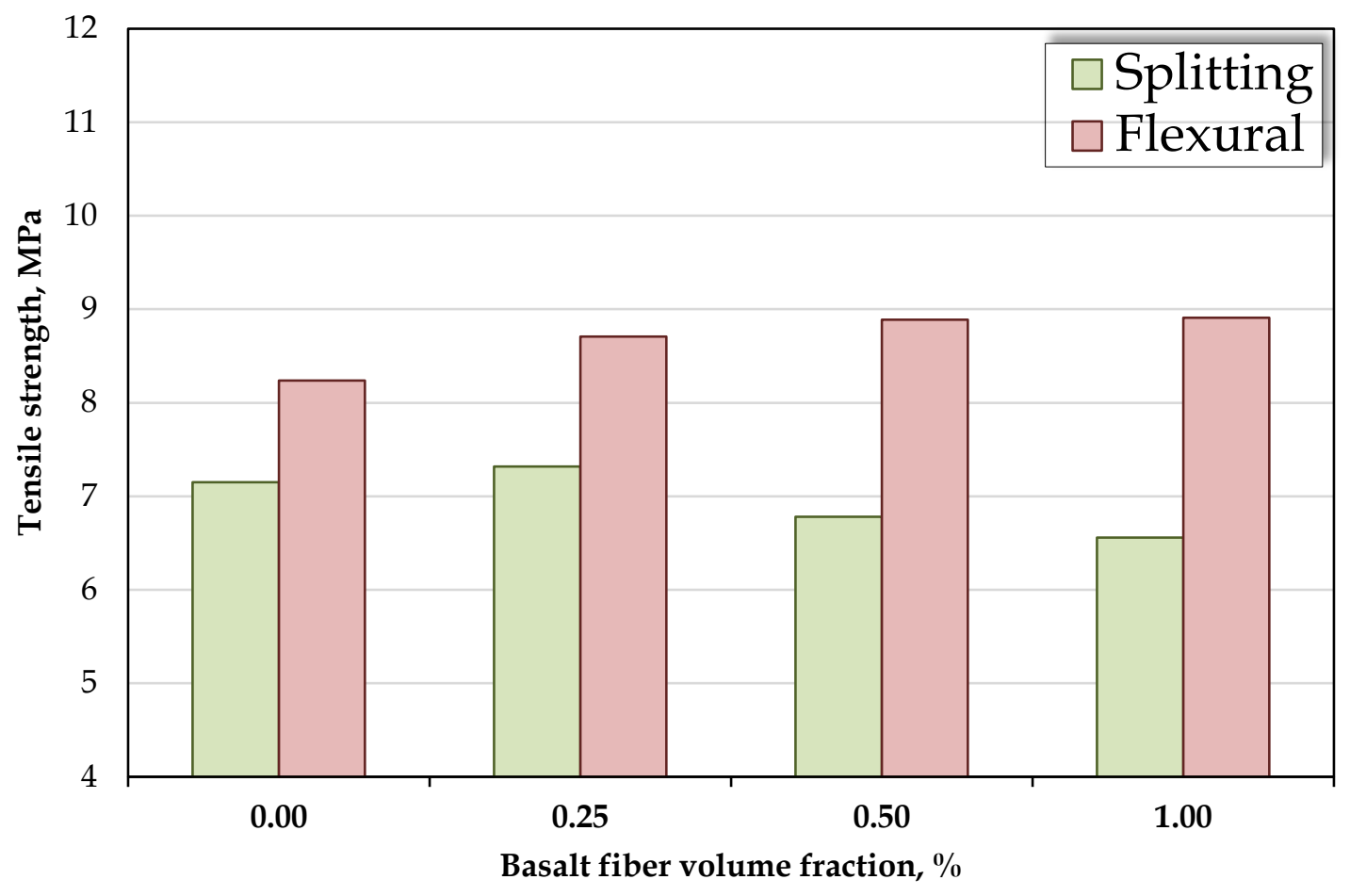

Fig. 19: Flexural strength of SCCs 


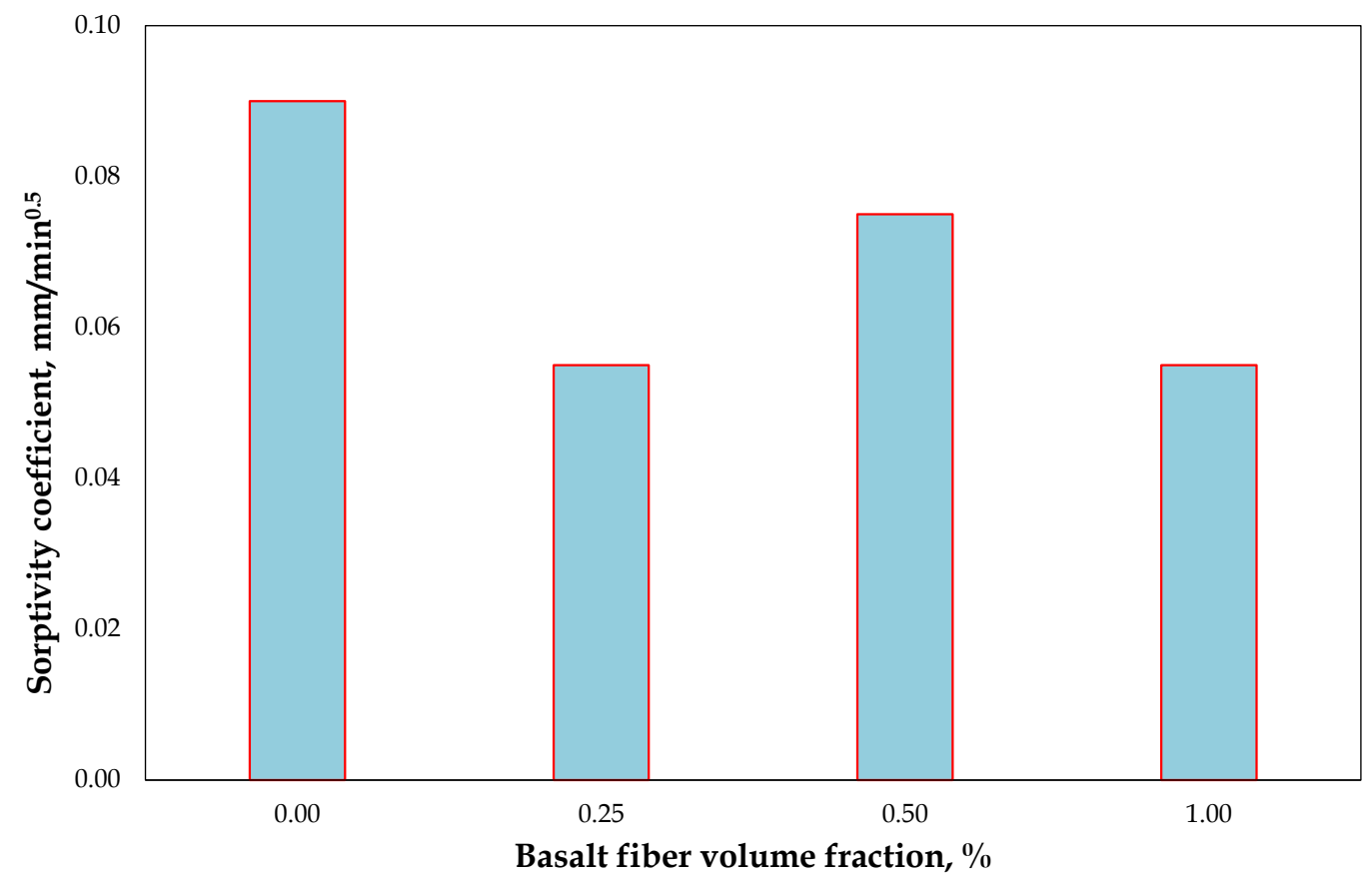

Fig. 20: Sorptivity coefficients versus basalt fiber volume fraction

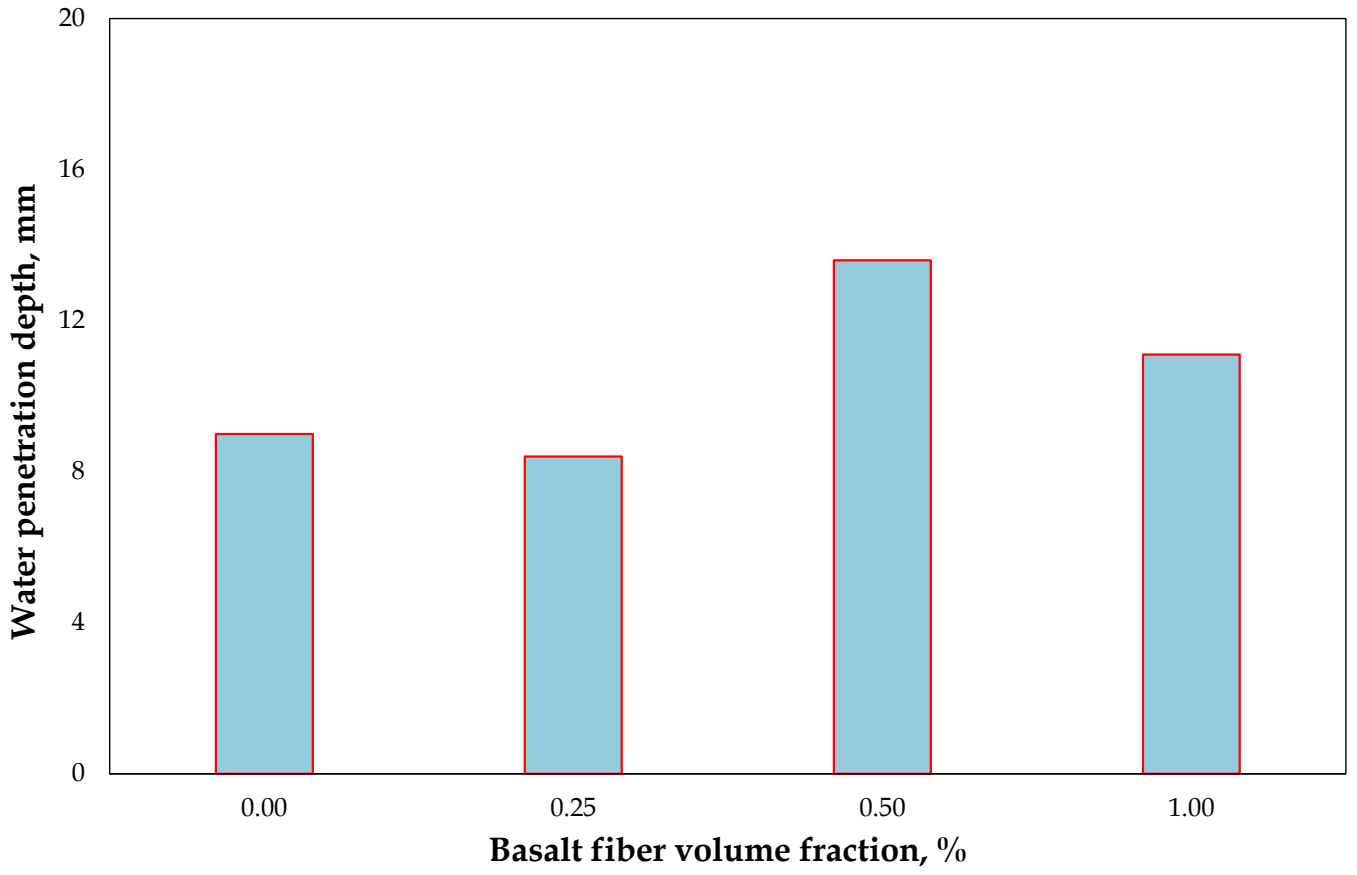

Fig. 21: Water penetration depth versus basalt fiber volume fraction 


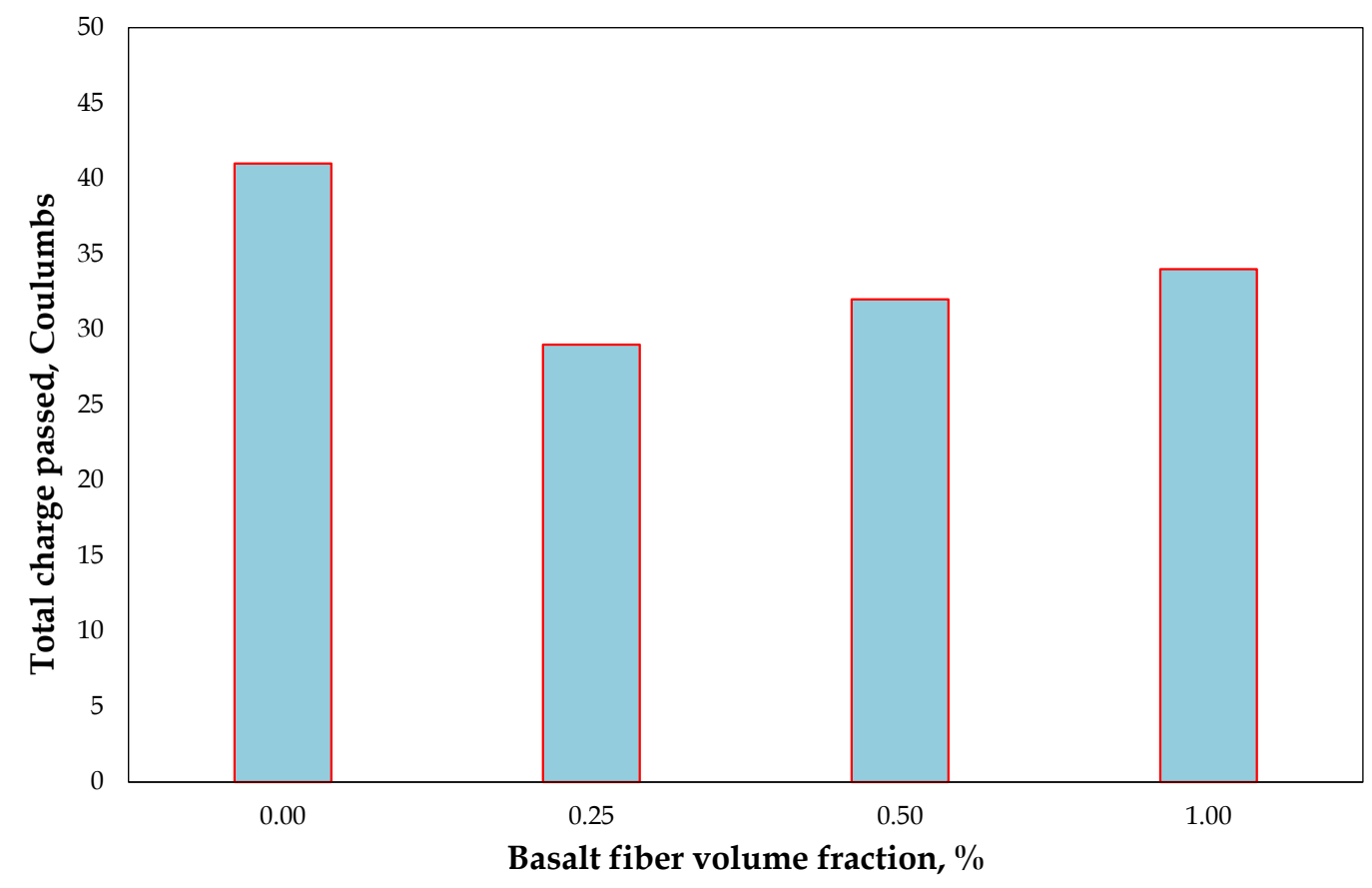

Fig. 22: Chloride ion penetration depth trend with respect to basalt fiber volume fraction 